\title{
Copy Number Variation detection from 1000 Genomes project exon capture sequencing data
}

\author{
Jiantao $\mathrm{Wu}^{1 \dagger}$, Krzysztof R Grzeda ${ }^{1 \dagger}$, Chip Stewart ${ }^{1}$, Fabian Grubert ${ }^{2}$, Alexander E Urban², Michael P Snyder ${ }^{2}$ \\ and Gabor T Marth ${ }^{1 *}$
}

\begin{abstract}
Background: DNA capture technologies combined with high-throughput sequencing now enable cost-effective, deep-coverage, targeted sequencing of complete exomes. This is well suited for SNP discovery and genotyping. However there has been little attention devoted to Copy Number Variation (CNV) detection from exome capture datasets despite the potentially high impact of CNVs in exonic regions on protein function.

Results: As members of the 1000 Genomes Project analysis effort, we investigated 697 samples in which 931 genes were targeted and sampled with 454 or Illumina paired-end sequencing. We developed a rigorous Bayesian method to detect CNVs in the genes, based on read depth within target regions. Despite substantial variability in read coverage across samples and targeted exons, we were able to identify 107 heterozygous deletions in the dataset. The experimentally determined false discovery rate (FDR) of the cleanest dataset from the Wellcome Trust Sanger Institute is $12.5 \%$. We were able to substantially improve the FDR in a subset of gene deletion candidates that were adjacent to another gene deletion call (17 calls). The estimated sensitivity of our call-set was $45 \%$.

Conclusions: This study demonstrates that exonic sequencing datasets, collected both in population based and medical sequencing projects, will be a useful substrate for detecting genic CNV events, particularly deletions. Based on the number of events we found and the sensitivity of the methods in the present dataset, we estimate on average 16 genic heterozygous deletions per individual genome. Our power analysis informs ongoing and future projects about sequencing depth and uniformity of read coverage required for efficient detection.
\end{abstract}

\section{Background}

Copy Number Variations (CNVs) i.e. deletions and amplifications, are an essential part of normal human variability [1]. Specific CNV events have also been linked to various human diseases [2], including cancer [3,4] autism [5,6] and schizophrenia [7]. Historically, large CNV events can be observed using FISH [8] but systematic, genome-wide discovery of $\mathrm{CNVs}$ started with microarray-based methods [9-11] which can detect events down to $1 \mathrm{~kb}$ resolution. As with all hybridization based approaches, these methods are blind in repetitive and low complexity regions of the genome where probes cannot be designed. High throughput sequencing with next-generation technologies have enabled CNV detection at higher resolution (i.e. down to smaller event size),

\footnotetext{
*Correspondence: marth@bc.edu

${ }^{\dagger}$ Equal contributors

'Boston College, Boston, Chestnut Hill, MA, USA

Full list of author information is available at the end of the article
}

in whole-genome shotgun datasets [12-14]. However, despite decreasing costs, deep-coverage $(\geq 25 \times)$ wholegenome data is still prohibitively expensive for routine sequencing of hundreds of samples, and in low-coverage (2-6x base coverage) datasets detection sensitivity and resolution is limited to long genomic events [1].

Targeted DNA capture technologies combined with high-throughput sequencing now provide a reasonable balance between coverage and sequencing cost in a substantial portion of the genome, and full-exome sequencing projects are presently collecting $\geq 25 \times$ average sequence coverage in thousands of samples. $\mathrm{CNV}$ events in exonic regions are important because the deletions of one or both copies, or amplifications affecting exons, are likely to incur phenotypic consequences.

Current algorithms for detecting CNVs in whole-genome shotgun sequencing data use one of four signals as evidence for an event: (1) aberrantly mapped mate-pair reads (RP or read pair methods); (2) split-read mapping positions (SR);

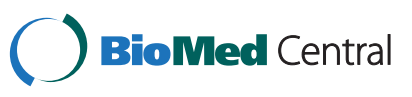


(3) de novo assembly (AS); and (4) a significant drop or increase of mapped read depth (RD methods). Unfortunately, these methods are not generally applicable for $\mathrm{CNV}$ detection in capture sequence data without substantial modifications. SR, RP, and AS based methods are sensitive only to CNVs in which mapped reads or fragments span the event breakpoint (s). In the case of exon capturing data, this restricts detection to $\mathrm{CNV}$ events where at least one breakpoint falls in a targeted exon. RD based methods suffer from large fluctuations of sequence coverage stemming from variability in probe-specific hybridization affinities across different capture targets (in this case: exons) and sets of such targets (in our case: genes), and from the overdispersion of the read coverage distribution in the same target across different samples. Presumably because of the technical challenges, and despite the importance of deletion or amplification events within exons, there are currently no reported CNV detection algorithms for targeted DNA capture based exon-sequencing data (with the exception of methods for tumor-normal datasets [15] where the read depth measured in the normal sample can be used for normalization - signal not available in the case of population sequencing).

In this study, we set out to develop a CNV detection algorithm for capture sequencing data. This algorithm is based on RD measurement, and detects samples with nonnormal copy number in the capture target regions. As participants of the 1000 Genomes Project, we took part in the data analysis of the "Exon Sequencing Pilot" dataset [16], where 12,475 exons from over 900 genes were targeted and sequenced with a variety of DNA capture and sequencing technologies.

\section{Results and discussion}

\section{Brief algorithmic overview}

Our algorithm is an extended version of RD-based CNV detection that aims to mitigate the vast target-to-target (and consequently gene-to-gene) heterogeneity of read coverage by normalization procedures roughly corresponding to those employed in CNV detection methods from microarray hybridization intensity data. The overall workflow of our method is shown in Figure 1 and described in greater detail in the Methods section. For a given gene in a given sample (we will use the abbreviation GSS: GeneSample Site throughout the paper), we define the read depth as the number of uniquely mapped reads whose $5^{\prime}$ end falls within any of the targeted exons within that gene. We compare this measurement with an expected read depth (Eq. 2, Methods), based on a "gene affinity" calculated from measured read depth for that gene across all
A
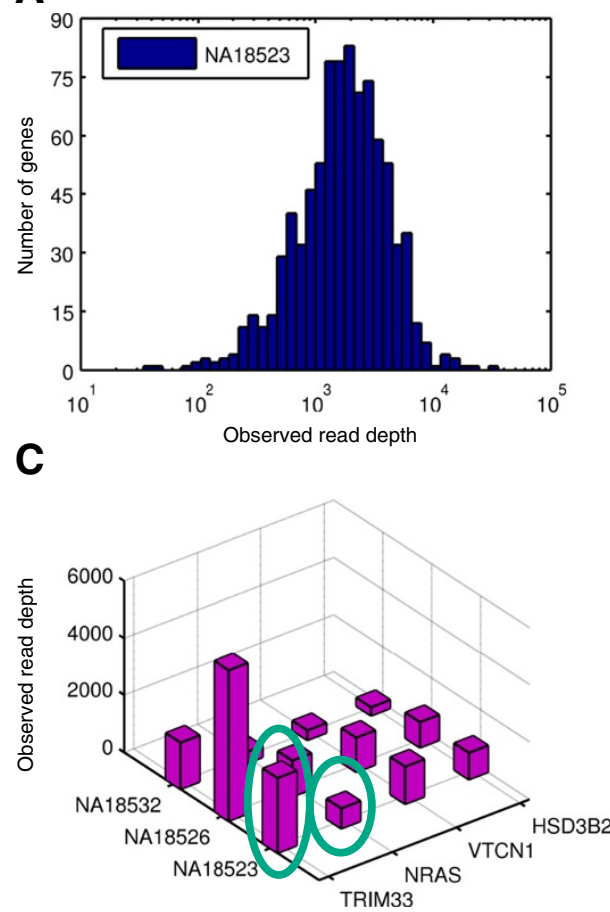

B
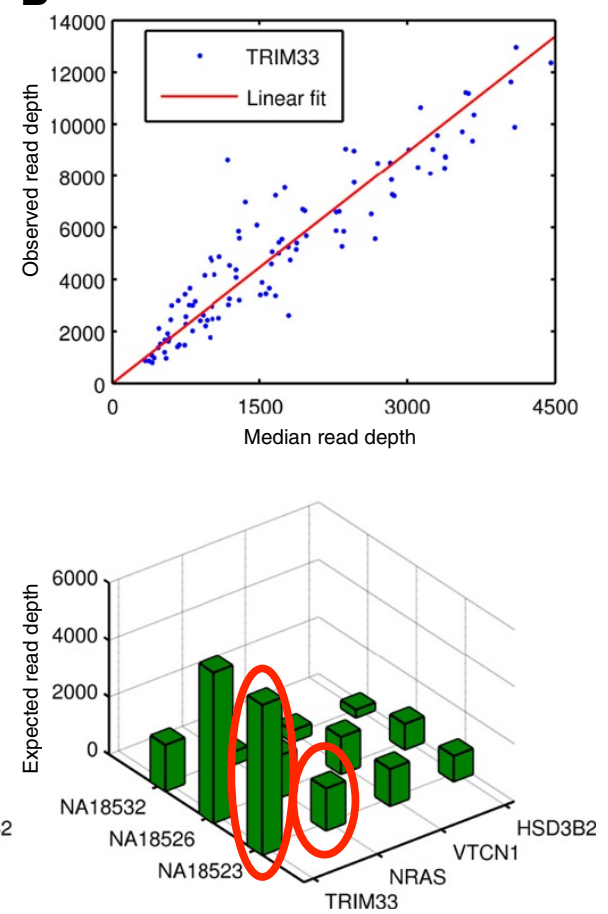

Figure 1 Workflow of the CNV detection method. A. Median Read Depth (MRD) is calculated for each sample, as a measure of sample coverage (NA18523 shown). B. The gene affinity is estimated for each gene as the slope of the least-square-error linear fit between MRD and RD for that gene (TRIM33 shown). C. Example of observed (magenta) and expected (green) read depth for three samples and four genes. The observed read depths were roughly half of the expected values for genes TRIM33 and NRAS, in sample NA18523, and detected as deletions. 
samples (to account for across-target read coverage variance due to target-specific hybridization), and the overall read depth for the sample (to account for the variance of read coverage due to the overall sequence quantity collected for the sample under examination). We then use a Bayesian scheme to determine whether the measured coverage is consistent with normal copy number (e.g. $\mathrm{CN}=2$ for autosomes), or aberrant copy number (i.e. homozygous deletion: $\mathrm{CN}=0$, heterozygous deletion: $\mathrm{CN}=1$, or amplification: $\mathrm{CN}>2$ ). We have included two algorithmic variants: One is suitable for $\mathrm{CNV}$ events that occur at a low allele frequency (i.e. in a small fraction of the samples), and the other for capturing higher-frequency deletion events (see Methods).

\section{Dataset}

In this study we analyzed the exon capture sequencing dataset collected by the 1000 Genomes Project Exon Sequencing Pilot, including 931 genes processed with Agilent liquid-phase and Nimblegen solid-phase capture methods, and sequenced from 697 individuals with Illumina paired-end and/or 454 technologies. The samples in the dataset have been sequenced by four different data collection centers (Washington University, WU; Wellcome Trust Sanger Institute, SC; Broad Institute, BI; and Baylor College of Medicine, BCM) using different pairings of capture and sequencing technologies (Table 1 and Table 2). As our method relies on an estimate of the gene-specific hybridization affinity, it requires that such affinities are consistent across all samples analyzed simultaneously. According to Principal Component Analysis of the observed read depths, (Figure 2A, see Methods), target and genes affinities are inconsistent across data from different centers, and therefore we analyzed each dataset separately. We only considered datasets with at least 100 samples (SC, BI, BCM) so we can obtain sufficient sample statistics across genes. After filtering out genes and samples that didn't meet our minimum read depth requirements (see Methods), we were left with the following datasets: SC (862 genes in 106 individuals sequenced with Illumina), BI (739 genes in 110 samples sequenced with Illumina), and BCM (439 genes in 349 samples sequenced with 454) (Table 1). The number of genes that passed our filters was substantially lower in the BCM dataset both due to lower overall 454 coverage (see below), and because the longer 454 reads result in lower RD (fewer reads) when compared to shorter Illumina reads, even at equivalent base coverage.

\section{Sample coverage and gene affinities}

As a metric of coverage for each sample, we calculated the sample-specific median gene RD, referred to as "Median Read Depth" (MRD); see Figure 1A and Methods. MRD was highest for the SC samples $(1,710 \pm 1,073$, median 1,491 reads/gene; data presented as mean \pm standard deviation), see Figure 2B. MRD was somewhat lower for the $\mathrm{BI}$ samples $(1,070 \pm 803$, median $860 \mathrm{reads} / \mathrm{gene})$, and much lower in the BCM dataset $(97 \pm 52$, median 87 reads/gene). As mentioned above, $\mathrm{RD}$ (distributed as in

Table 1 Properties of datasets from different sequencing centers

\begin{tabular}{|c|c|c|c|c|}
\hline & SC & BCM & BI & WU \\
\hline Total sample count & 117 & 352 & 161 & 93 \\
\hline Sample count after quality control & 106 & 349 & 110 & 82 \\
\hline Technology & Illumina & 454 & Illumina & Illumina \\
\hline Duplicate rate & 0.21 & 0.30 & 0.50 & 0.72 \\
\hline Mapping quality (mean) & 50 & 33 & 45 & 51 \\
\hline Base coverage(mean \pm standard deviation) & $56 \pm 34$ & $23 \pm 12$ & $70 \pm 61$ & $29 \pm 9$ \\
\hline Read depth per gene(mean \pm standard deviation) & $2309 \pm 3166$ & $106 \pm 171$ & $1329 \pm 2053$ & $977 \pm 1382$ \\
\hline $\mathrm{MRD}($ mean \pm standard deviation $)$ & $1710 \pm 1073$ & $97 \pm 52$ & $1070 \pm 803$ & $599 \pm 164$ \\
\hline Number of exons & 8174 & 8174 & 8174 & 8174 \\
\hline Exons overlapped with segmental duplication regions & $458(5.6 \%)$ & $458(5.6 \%)$ & $458(5.6 \%)$ & $458(5.6 \%)$ \\
\hline Number of genes (passing QC) & 862 & 439 & 739 & 1 \\
\hline Genes overlapped with segmental duplication regions & $29(3.3 \%)$ & $11(2.5 \%)$ & $23(3.1 \%)$ & $0(0.0 \%)$ \\
\hline Over-dispersion factor(mean \pm standard deviation) & $7.9 \pm 8.2$ & $2.1 \pm 1.1$ & $6.4 \pm 5.5$ & $\mathrm{~N} / \mathrm{A}$ \\
\hline Quality index(mean \pm standard deviation) & $9.4 \pm 8.8$ & $5.5 \pm 2.3$ & $7.6 \pm 5.6$ & $\mathrm{~N} / \mathrm{A}$ \\
\hline Expected detection sensitivity based on quality index & 0.46 & 0.20 & 0.41 & $\mathrm{~N} / \mathrm{A}$ \\
\hline Number of calls $h=0.65$ either with or without a neighboring call & 36 & 4 & 56 & $\mathrm{~N} / \mathrm{A}$ \\
\hline Number of callsh $=0.1$ either with a neighboring call & 17 & 0 & 11 & N/A \\
\hline
\end{tabular}


Table 2 Data characteristized by sequencing center and population

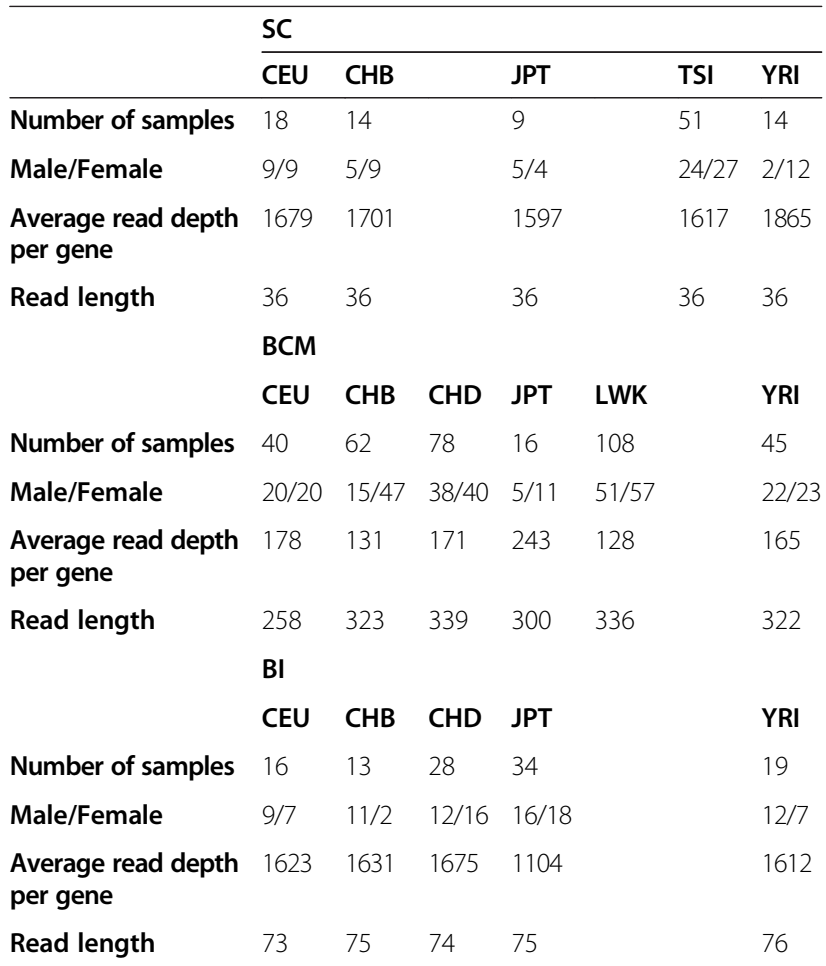

Population abbreviations:

CEU - Utah residents with Northern and Western European ancestry

$\mathrm{CHB}$ - Han Chinese in Beijing.

CHD - Chinese in Denver, Colorado.

JPT - Japanese in Tokyo, Japan.

LWK - Luhya in Webuye, Kenya.

TSI - Toscans in Italy.

YRI - Yoruba in Ibadan, Nigeria.

Figure $2 \mathrm{C}$ ) is not determined by base coverage alone. Base coverage was highest in the BI data $(70 \pm 61$, median 56 reads/base), followed by SC (56 \pm 34 , median 50 reads/ base). The much lower RD in the 454 reads from $\mathrm{BCM}$ corresponds to only somewhat lower base coverage (23 \pm 12 , median 21 reads/base).

For each target we define a quantity, the "target affinity", intended to describe the number of reads (RD) being mapped to a given target, relative to the sample-specific MRD over all capture targets. Analogously, we define the gene-specific affinity as the ratio of the number of reads (RD) mapped to the targets (exons) belonging to that gene and the gene-specific MRD for that same sample (see Methods, Figure 2D). In general, tighter distributions of affinities, with mean and median as close to 1 as possible, are desirable because these correspond to more even target coverage. The observed gene affinities for our datasets (Figure 2D) were as follows: SC $(1.40 \pm 1.43$, median 1.04), BI $(1.58 \pm 1.59$, median 1.20), and BCM $(2.63 \pm 3.03$, median 1.73). Because of the more favorable gene affinities, we used the SC data as our primary dataset for method development and experimental validations.

\section{CNV candidates detected in the data}

According to our Bayesian detection scheme, we call a heterozygous deletion event in a gene if the posterior probability value of $\mathrm{CN}=1$, i.e. $\mathrm{P}(\mathrm{CN}=1 \mid \mathrm{RD}) \geq h$ where $h$ is a pre-defined probability cutoff value. Similarly, a homozygous deletion is where $\mathrm{P}(\mathrm{CN}=0 \mid \mathrm{RD}) \geq h$. Although we detected both deletions and amplifications in the analyzed datasets, deletion events (even when in a heterozygous state) provide easier detectable signal than amplifications. For this reason we only discuss deletion events here and report candidate amplifications in Table 3.

Using a cutoff value $h=0.65$, we detected deletion 96 events in the three datasets (36 in SC, 56 in BI, and 4 in $\mathrm{BCM}$ ), all heterozygous deletions (Table 4, Table 5 and Table 6). The top ranked deletions are shown in Figure 3A. Most of the events were found in the Tuscan population, which constituted about half of the sample set. 10 of 36 gene deletions in the SC dataset were found in two samples (NA18523 and NA20533), clustered in a contiguous string of deleted genes extending approximately $3 \mathrm{Mb}$ on chromosome 1 and 17, respectively, a genomic deletion event that we were also able to find in the 1000 Genomes Project whole-genome Low Coverage Pilot data [16] from the same samples (data not shown).

When two or more gene deletions are detected in close proximity, it is likely that these events are part of a single, longer genomic deletion spanning the genes. With this in mind, we searched the sequenced genes for deletion events at a lower probability cutoff value ( $h=0.1$ ), but required that an immediate neighbor of a candidate gene be located within $3 \mathrm{Mbp}$ and also show evidence for a deletion at the same probability cutoff. This procedure produced 17 heterozygous deletion calls in the SC dataset, 11 calls in the BI dataset (but no such calls were made in the BCM dataset). The union of both callsets (i.e. those made with and without use of neighboring information) resulted in a total of 107 unique deletion events (41 in SC dataset, 62 in BI, and 4 in BCM).

We note that none of the events we detected in our data were at high allele frequency. In fact, even the most "common" events were only present in two samples, as heterozygotes.

\section{Call-set accuracy assessment}

To assess the accuracy of deletion calls made in the SC dataset, we performed experimental validations on calls made with posterior probability $\geq 0.65$ without neighbor information, using qPCR (see Methods). The validation results are summarized in Figure 3B. Of the 36 calls made, we evaluated 26 . All 22 calls with posterior probability $\geq 0.95$ and 4 out of 12 calls (randomly selected) with posterior probability between 0.65 and 0.95 were submitted for validation. 6 were considered positively validated as they appeared in an earlier publication [17] 

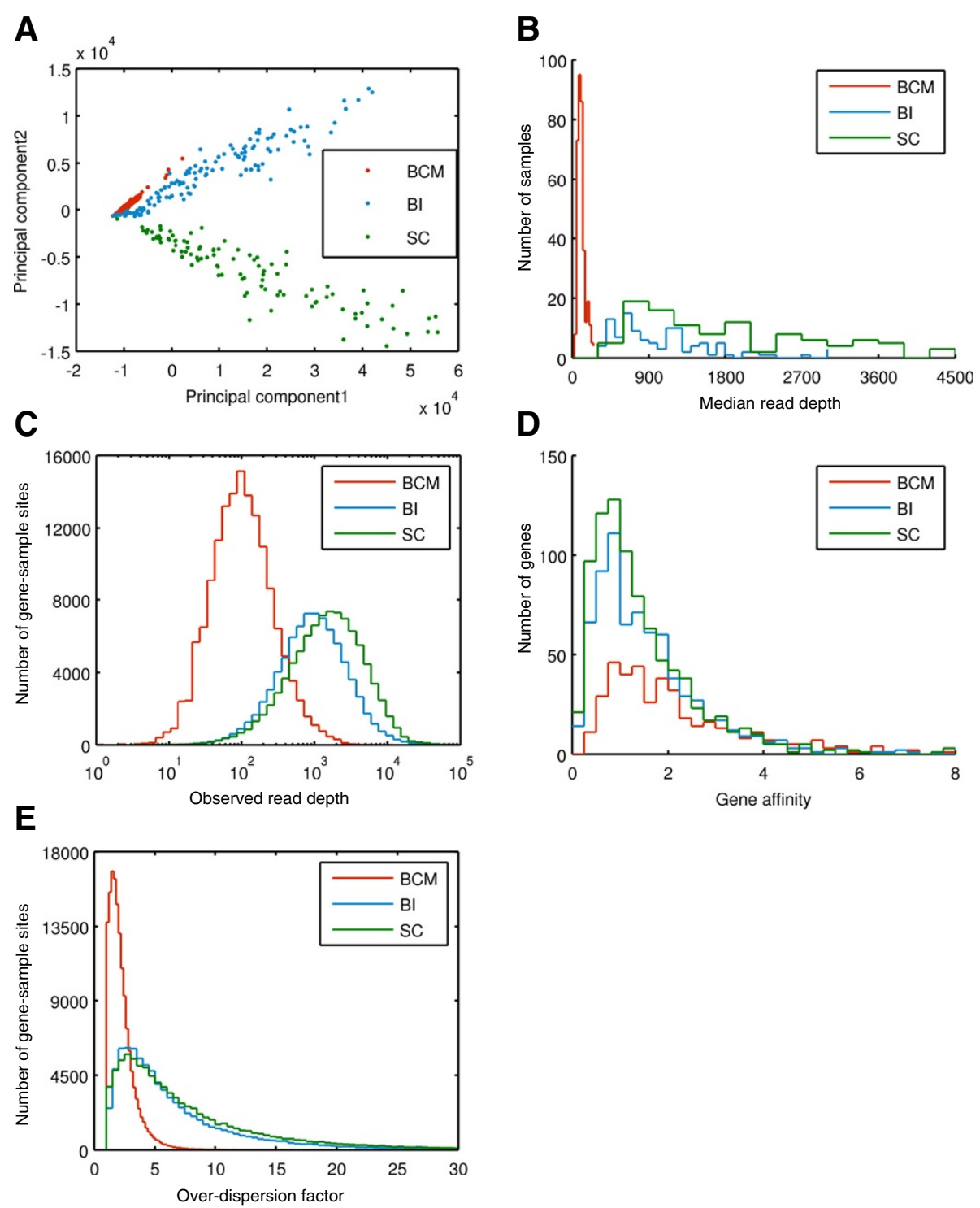

Figure 2 Data characteristics for the 1000 genomes exon sequencing pilot datasets. A. Principal component analysis of a "mixed" read depth matrix built with data from 3 different sequencing centers, SC (Wellcome Trust Sanger Institute), BI (Broad Institute) and BCM (Baylor College of Medicine). Each sample is represented as a point in the plot, with the first principal component plotted vs. the second principal component. Samples from different sequencing centers cluster separately from each other within this space, suggesting significant differences in the gene affinities among these three datasets. B. Distributions of MRD for each of the BCM, BI and SC samples $\mathbf{C}$. Histogram of RD across all GSSs in the three datasets. D. Histogram of gene affinities across genes within each of the three datasets. E. Distributions of the RD over-dispersion factor (ODF) in our data.

and 20 were validated de novo using qPCR. The qPCR validations produced positive results for 12 calls (measured fold change $<0.7$ ) and negative results for 3 calls (measured fold change $>0.8$ ). The validation results for the remaining 5 were inconclusive. All the 17 neighbored calls with posterior probability $\geq 0.1$ were selected for validation. 7 were considered valid per previous publication [17], 7 were positively validated de novo and none was found invalid; validation was not obtained for the remaining 3 . The union of those two callsets counted 41 calls and 32 of them were evaluated. Among these 32 calls 7 were considered positively validated per previous publication [17], 14 were positively validated de novo, 3 were invalidated, 5 were inconclusive and 3 did not obtain the validation results. The numbers of validated calls are presented in Table 7. The selection procedure for site validation was as follows: (1) We selected sites for validation (in some categories, all candidates, in others, a random selection); (2) we searched the literature, and removed from the validation list events that we 
Table 3 Gene duplication calls in the SC dataset

\begin{tabular}{|c|c|c|c|c|c|c|c|c|c|}
\hline Population & Sample & Gene name & Gene function & Chr & Start [bp] & End [bp] & $\begin{array}{l}\text { Posterior } \\
\text { probablity }\end{array}$ & $R D_{\text {observed }}$ & $R D_{\text {expected }}$ \\
\hline CEU & NA12348 & CD300LB & CD300 molecule-like family member b & 17 & 70030472 & 70039195 & 1.000 & 638 & 420 \\
\hline TSI & NA20533 & CLDN10 & claudin 10 & 13 & 95003009 & 95028269 & 1.000 & 2108 & 1582 \\
\hline $\mathrm{CHB}$ & NA18526 & SNRNP27 & $\begin{array}{l}\text { small nuclear ribonucleoprotein } 27 \mathrm{kDa} \\
\text { (U4/U6.U5) }\end{array}$ & 2 & 69974621 & 69977184 & 1.000 & 530 & 383 \\
\hline $\mathrm{CHB}$ & NA18532 & CES1 & $\begin{array}{l}\text { carboxylesterase } 1 \text { (monocyte/macrophage } \\
\text { serine esterase 1) }\end{array}$ & 16 & 54401930 & 54424468 & 1.000 & 501 & 337 \\
\hline TSI & NA20752 & NOM1 & nucleolar protein with MIF4G domain 1 & 7 & 156435193 & 156455158 & 1.000 & 1335 & 966 \\
\hline TSI & NA20796 & AHNAK & AHNAK nucleoprotein & 11 & 62040792 & 62059238 & 1.000 & 7330 & 5169 \\
\hline TSI & NA20796 & ZNF264 & zinc finger protein 264 & 19 & 62408577 & 62416161 & 0.999 & 1276 & 888 \\
\hline TSI & NA20801 & GPR128 & G protein-coupled receptor 128 & 3 & 101811391 & 101896535 & 0.998 & 14747 & 8265 \\
\hline TSI & NA20772 & STX16 & syntaxin 16 & 20 & 56660469 & 56684753 & 0.998 & 2101 & 1605 \\
\hline TSI & NA20769 & MRPS6 & mitochondrial ribosomal protein S6 & 21 & 34419511 & 34436770 & 0.998 & 1585 & 1203 \\
\hline TSI & NA20774 & ELAVL4 & $\begin{array}{l}\text { ELAV (embryonic lethal, abnormal vision, } \\
\text { Drosophila)-like } 4 \text { (Hu antigen D) }\end{array}$ & 1 & 50383216 & 50439437 & 0.998 & 782 & 567 \\
\hline TSI & NA20804 & CYP2A13 & $\begin{array}{l}\text { cytochrome P450, family 2, subfamily A, } \\
\text { polypeptide } 13\end{array}$ & 19 & 46291375 & 46293686 & 0.997 & 1289 & 984 \\
\hline TSI & NA20774 & CREB5 & CAMP responsive element binding protein 5 & 7 & 28494318 & 28825421 & 0.996 & 1435 & 954 \\
\hline TSI & NA20796 & ZNF32 & zinc finger protein 32 & 10 & 43459504 & 43461587 & 0.996 & 911 & 646 \\
\hline TSI & NA20520 & C6orf145 & chromosome 6 open reading frame 145 & 6 & 3668852 & 3683381 & 0.995 & 2015 & 1601 \\
\hline CEU & NA12348 & GDNF & glial cell derived neurotrophic factor & 5 & 37851510 & 37870647 & 0.994 & 306 & 217 \\
\hline $\mathrm{CHB}$ & NA18561 & PSMB4 & $\begin{array}{l}\text { proteasome (prosome, macropain) subunit, } \\
\text { beta type, } 4\end{array}$ & 1 & 149638688 & 149640730 & 0.986 & 3461 & 2216 \\
\hline CEU & NA12546 & DAZAP2 & DAZ associated protein 2 & 12 & 49920394 & 49922509 & 0.985 & 2265 & 1651 \\
\hline TSI & NA20752 & AATF & apoptosis antagonizing transcription factor & 17 & 32380539 & 32488077 & 0.976 & 1157 & 843 \\
\hline CEU & NA12749 & PAQR5 & $\begin{array}{l}\text { progestin and adipoQ receptor family } \\
\text { member } V\end{array}$ & 15 & 67439474 & 67483215 & 0.976 & 1684 & 1239 \\
\hline TSI & NA20769 & BCL2L11 & BCL2-like 11 (apoptosis facilitator) & 2 & 111597794 & 111638279 & 0.965 & 1813 & 1435 \\
\hline TSI & NA20804 & PILRA & paired immunoglobin-like type 2 receptor alpha & 7 & 99809603 & 99835466 & 0.909 & 962 & 752 \\
\hline TSI & NA20589 & C8orf85 & chromosome 8 open reading frame 85 & 8 & 118019664 & 118024121 & 0.903 & 147 & 91 \\
\hline TSI & NA20752 & CCKAR & cholecystokinin A receptor & 4 & 26092358 & 26100987 & 0.902 & 712 & 532 \\
\hline JPT & NA18973 & HBG2 & hemoglobin, gamma G & 11 & 5278820 & 5523329 & 0.901 & 4151 & 3094 \\
\hline TSI & NA20774 & HIPK1 & homeodomain & 1 & 114298778 & 114317657 & 0.900 & 2374 & 1626 \\
\hline TSI & NA20774 & ODC1 & ornithine decarboxylase 1 & 2 & 10498301 & 10502609 & 0.897 & 1489 & 935 \\
\hline TSI & NA20796 & STBD1 & starch binding domain 1 & 4 & 77446947 & 77450177 & 0.885 & 978 & 664 \\
\hline TSI & NA20589 & CRIPAK & cysteine-rich PAK1 inhibitor & 4 & 1378300 & 1379640 & 0.877 & 76 & 38 \\
\hline YRI & NA19189 & PSMB4 & $\begin{array}{l}\text { proteasome (prosome, macropain) subunit, } \\
\text { beta type, } 4\end{array}$ & 1 & 149638688 & 149640730 & 0.853 & 2622 & 2090 \\
\hline TSI & NA20774 & STX16 & syntaxin 16 & 20 & 56660469 & 56684753 & 0.811 & 949 & 704 \\
\hline JPT & NA18980 & CES1 & $\begin{array}{l}\text { carboxylesterase } 1 \text { (monocyte/macrophage } \\
\text { serine esterase 1) }\end{array}$ & 16 & 54401930 & 54424468 & 0.788 & 1679 & 1036 \\
\hline TSI & NA20774 & PAQR5 & $\begin{array}{l}\text { progestin and adipoQ receptor family } \\
\text { member } V\end{array}$ & 15 & 67439474 & 67483215 & 0.788 & 1048 & 676 \\
\hline $\mathrm{CHB}$ & NA18561 & CRNN & cornulin & 1 & 150648694 & 150651333 & 0.778 & 4845 & 3172 \\
\hline TSI & NA20774 & DKK4 & dickkopf homolog 4 (Xenopus laevis) & 8 & 42350775 & 42353720 & 0.760 & 493 & 362 \\
\hline
\end{tabular}


Table 3 Gene duplication calls in the SC dataset (Continued)

\begin{tabular}{|c|c|c|c|c|c|c|c|c|c|}
\hline TSI & NA20589 & NOM1 & nucleolar protein with MIF4G domain 1 & 7 & 156435193 & 156455158 & 0.740 & 1052 & 801 \\
\hline TSI & NA20769 & RNF122 & ring finger protein 122 & 8 & 33525813 & 33535831 & 0.734 & 2574 & 2004 \\
\hline TSI & NA20796 & ZNF521 & zinc finger protein 521 & 18 & 20896674 & 21184908 & 0.721 & 3536 & 2738 \\
\hline TSI & NA20769 & VLDLR & very low density lipoprotein receptor & 9 & 2625453 & 2631499 & 0.676 & 2092 & 1624 \\
\hline
\end{tabular}

found as validated in one of the publications we consulted; (3) events that remained on the list were sent for experimental validation. The overall FDR for the union of calls made with and without neighboring information can be estimated as $12.5 \%(3 / 24)$.

\section{Sensitivity}

We performed simulations to assess the detection efficiency of our method, both for individual gene and for pairs of neighboring genes deletions. Specifically, in each sample we randomly selected (a) 5 out of 862 genes in one simulation and (b) 5 pairs of neighboring genes in another simulation. In the selected genes we downsampled the actual read depth seen in the experimental data by a factor of 2 to simulate a heterozygous deletion. The results of those simulations are presented in Figure 3C. Of the 530 gene deletions, we detected 237 (45\%). Of the 530 gene-pair deletions we detected 287 (54\%). We also performed simulations on smaller subsets of the original 106 samples to assess the impact of sample size on detection sensitivity. Reduction of sample size did not substantially degrade detection sensitivity as long as the number of samples was $>20$. Therefore, our detection efficiency is $40-45 \%$ without using neighboring information and approximately $50-55 \%$ with the use of neighboring information, in the SC dataset.

In addition to simulations, we compared our dataset to a published study [17]. This study reported 12 heterozygous deletion events in samples and genes (in our terminology, GSS) that were part of our analyzed dataset. We detected 6 of these 12 events, which is broadly consistent with our overall sensitivity estimate.

Finally, we investigated our sensitivity to common events (see Methods) using simulations. Figure 3D shows detection sensitivity as a function of gene-level affinity: for a gene affinity value of 1.8 (representing the $75^{\text {th }}$ percentile of our data), sensitivity to common events (allele frequency between $10 \%$ and $90 \%$ ) approaches $40 \%$. Note that the detection efficiency starts to decrease at high allele frequency $(>70 \%)$ due to a reduction of the overall read depth because more samples have a deletion and a corresponding depleted read depth signal. We can also see that the median gene affinity is substantially lower than the mean because the distribution of gene affinity has a long tail at the high end (Figure 2D). Since sensitivity is directly related to the gene affinity, the simulated data with the substantially higher mean gene affinity (red) has better sensitivity than with the substantially lower median gene affinity (green).

\section{The number of CNV events in the samples}

We estimated the total number of gene deletions in the SC dataset from the number of detected events (41), the FDR (12.5\%) and the detection efficiency (45\%), as $~ 66$, or a nominal 0.62 deletions per sample. By projecting the per-sample number, corresponding to $3.9 \%$ of the exome (862 genes of 21,999$)$, onto the whole exome, our estimate for the average number of genic deletion events is $16 \pm 4$ per sample. This estimation is representative for the whole-exome sequencing data since the 1000 Genomes Exon Pilot Project randomly selected all the exon targets from the CCDS collection. Our gene set is therefore a quasi-random sampling of known human genes, with no intentional enrichment for any given gene family. Figure $4 \mathrm{~A}$ and $\mathrm{B}$ show the distributions of exon length in the gene list used for our analysis and the full human exome. There is no significant difference between these two distributions: the median and the standard deviation of the exon length for our study are $125 \mathrm{bp}$ and $236 \mathrm{bp}$, whereas the corresponding values for the whole exome are $127 \mathrm{bp}$ and $264 \mathrm{bp}$. The similarity of these two distributions suggests that our estimation of the number of events per sample is unbiased and is representative for a whole-exome analysis.

\section{Detection efficiency as a function of data quantity and data quality}

As discussed earlier, our algorithm's sensitivity was 45\% at $\sim 87.5 \%$ accuracy. Both sensitivity and accuracy are considerably lower than achievable for SNP detection in the same datasets [16]. This poses the more general question of how detection efficiency is influenced by sample size, data quantity, and data quality. Our simulations show that sensitivity only modestly depends on sample size, above approximately 20 samples (Figure $3 \mathrm{C}$ ).

We found that the primary factors that determine detection efficiency are (i) sequence coverage, or more precisely, RD (higher RD supplies more statistical power to detect systematic changes in coverage); (ii) the level of over-dispersion of the RD distribution for individual genes (the more the RD distribution departs from an expected Poisson distribution, the less one can rely on the statistics); and (iii) the shape of the distribution of $\mathrm{RD}$ across all genes in the dataset, determined by the 
Table 4 Gene deletion calls in the SC dataset

\begin{tabular}{|c|c|c|c|c|c|c|c|c|c|}
\hline Population & Sample & Gene name & Gene function & $\mathrm{Chr}$ & Start [bp] & End [bp] & $\begin{array}{l}\text { Posterior } \\
\text { probability }\end{array}$ & $R D_{\text {observed }}$ & $R D_{\text {expected }}$ \\
\hline YRI & NA18523 & BCL2L15 & BCL2-like 15 & 1 & 114225268 & 114231520 & 1.000 & 533 & 1158 \\
\hline YRI & NA18523 & HIPK1 & homeodomain interacting protein kinase 1 & 1 & 114298778 & 114317657 & 1.000 & 2539 & 5272 \\
\hline TSI & NA20533 & GLOD4 & glyoxalase domain containing 4 & 17 & 610163 & 632245 & 1.000 & 1322 & 2295 \\
\hline TSI & NA20533 & C1QBP & $\begin{array}{l}\text { complement component 1, q subcomponent } \\
\text { binding protein }\end{array}$ & 17 & 5277059 & 5282317 & 1.000 & 793 & 1416 \\
\hline TSI & NA20533 & C17orf91 & chromosome 17 open reading frame 91 & 17 & 1562414 & 1563890 & 1.000 & 369 & 574 \\
\hline YRI & NA18523 & NRAS & $\begin{array}{l}\text { neuroblastoma RAS viral (v-ras) oncogene } \\
\text { homolog }\end{array}$ & 1 & 115052679 & 115060304 & 1.000 & 702 & 1462 \\
\hline YRI & NA18523 & TRIM33 & tripartite motif-containing 33 & 1 & 114741793 & 114808533 & 1.000 & 2610 & 5225 \\
\hline TSI & NA20533 & TRPV3 & $\begin{array}{l}\text { transient receptor potential cation channel, } \\
\text { subfamily } \mathrm{V} \text {, member } 3\end{array}$ & 17 & 3363961 & 3404894 & 1.000 & 3365 & 5275 \\
\hline TSI & NA20774 & PTMAP1 & $\begin{array}{l}\text { prothymosin, alpha pseudogene } 1 \\
\text { (gene sequence 26) }\end{array}$ & 6 & 30725671 & 30728671 & 1.000 & 132 & 260 \\
\hline TSI & NA20796 & SNRNP27 & $\begin{array}{l}\text { small nuclear ribonucleoprotein } 27 \mathrm{kDa} \\
\text { (U4/U6.U5) }\end{array}$ & 2 & 69974621 & 69977184 & 0.998 & 105 & 194 \\
\hline TSI & NA20807 & HIST1H2BC & histone cluster 1, H2bc & 6 & 26231731 & 26232111 & 0.998 & 42 & 90 \\
\hline TSI & NA20772 & ULBP1 & UL16 binding protein 1 & 6 & 150331436 & 150332954 & 0.997 & 104 & 205 \\
\hline TSI & NA20807 & CYP2A13 & $\begin{array}{l}\text { cytochrome P450, family } 2 \text {, subfamily A, } \\
\text { polypeptide } 13\end{array}$ & 19 & 46291375 & 46293686 & 0.996 & 126 & 204 \\
\hline YRI & NA18508 & PTMAP1 & $\begin{array}{l}\text { prothymosin, alpha pseudogene } 1 \\
\text { (gene sequence 26) }\end{array}$ & 6 & 30725671 & 30728671 & 0.992 & 145 & 230 \\
\hline CEU & NA07000 & PSG8 & pregnancy specific beta-1-glycoprotein 8 & 19 & 47950287 & 47960273 & 0.990 & 29 & 70 \\
\hline CEU & NA11893 & PSG8 & pregnancy specific beta-1-glycoprotein 8 & 19 & 47950287 & 47960273 & 0.985 & 43 & 86 \\
\hline TSI & NA20771 & PTMAP1 & $\begin{array}{l}\text { prothymosin, alpha pseudogene } 1 \\
\text { (gene sequence 26) }\end{array}$ & 6 & 30725671 & 30728671 & 0.980 & 533 & 862 \\
\hline TSI & NA20773 & CCK & cholecystokinin & 3 & 42274594 & 42280126 & 0.971 & 282 & 474 \\
\hline CEU & NA07000 & HMGN4 & $\begin{array}{l}\text { high mobility group nucleosomal binding } \\
\text { domain } 4\end{array}$ & 6 & 26653414 & 26653686 & 0.966 & 68 & 132 \\
\hline CEU & NA12749 & HMGN4 & $\begin{array}{l}\text { high mobility group nucleosomal binding } \\
\text { domain } 4\end{array}$ & 6 & 26653414 & 26653686 & 0.966 & 156 & 286 \\
\hline TSI & NA20772 & AlF1 & allograft inflammatory factor 1 & 6 & 31692086 & 31692262 & 0.964 & 51 & 124 \\
\hline CEU & NA12348 & DUSP10 & dual specificity phosphatase 10 & 1 & 219942377 & 219946216 & 0.962 & 155 & 242 \\
\hline YRI & NA18508 & ULBP1 & UL16 binding protein 1 & 6 & 150331436 & 150332954 & 0.941 & 40 & 79 \\
\hline YRI & NA18523 & PPM1J & $\begin{array}{l}\text { protein phosphatase, } \mathrm{Mg} 2+/ \mathrm{Mn} 2+ \\
\text { dependent, } 1 \mathrm{~J}\end{array}$ & 1 & 113056116 & 113057756 & 0.891 & 560 & 924 \\
\hline TSI & NA20807 & POU5F1 & POU class 5 homeobox 1 & 6 & 31240884 & 31241803 & 0.891 & 124 & 193 \\
\hline TSI & NA20772 & SERPINA11 & $\begin{array}{l}\text { serpin peptidase inhibitor, clade A (alpha-1 } \\
\text { antiproteinase, antitrypsin), member } 11\end{array}$ & 14 & 93978696 & 93984864 & 0.889 & 786 & 1243 \\
\hline CEU & NA07000 & KRT18P19 & keratin 18 pseudogene 19 & 12 & 51630379 & 51632393 & 0.887 & 85 & 174 \\
\hline CEU & NA12348 & ULBP1 & UL16 binding protein 1 & 6 & 150331436 & 150332954 & 0.879 & 49 & 88 \\
\hline YRI & NA18523 & $\mathrm{RHOC}$ & ras homolog gene family, member $C$ & 1 & 113054308 & 113055529 & 0.867 & 557 & 955 \\
\hline CEU & NA12348 & STBD1 & starch binding domain 1 & 4 & 77446947 & 77450177 & 0.839 & 246 & 395 \\
\hline CEU & NA07000 & POU5F1 & POU class 5 homeobox 1 & 6 & 31240884 & 31241803 & 0.823 & 106 & 169 \\
\hline CEU & NA12749 & SNRNP27 & $\begin{array}{l}\text { small nuclear ribonucleoprotein } 27 \mathrm{kDa} \\
\text { (U4/U6.U5) }\end{array}$ & 2 & 69974621 & 69977184 & 0.775 & 142 & 216 \\
\hline TSI & NA20752 & POU5F1 & POU class 5 homeobox 1 & 6 & 31240884 & 31241803 & 0.723 & 76 & 142 \\
\hline
\end{tabular}


Table 4 Gene deletion calls in the SC dataset (Continued)

\begin{tabular}{llllllllll}
\hline TSI & NA20807 & HIST1H2BO & histone cluster 1, H2bo & 6 & 27969220 & 27969600 & 0.723 & 48 & 88 \\
TSI & NA20589 & POU5F1 & POU class 5 homeobox 1 & 6 & 31240884 & 31241803 & 0.697 & 61 & 117 \\
TSI & NA20786 & NPSR1 & neuropeptide S receptor 1 & 7 & 34884213 & 34884321 & 0.678 & 51 & 88 \\
\hline
\end{tabular}

gene affinities (uneven distribution means that detection power is low in a high fraction of the genes, but this effect is not compensated by the extra coverage in other, "over-sequenced" genes where detection efficiency is already high, see Figure 5A below. Favorable scenarios therefore involve distributions in which all or most genes have sufficient RD for detection).

For each gene, we compute a quality index (QI) taking into account the variance of the expected read depth for that gene (assuming the ideal, Poisson distribution), $R D_{\text {exp }}$, and a over-dispersion factor, ODF, that quantifies the over-dispersion of $\mathrm{RD}$ relative to the Poisson expectation:

$$
Q I=\frac{\sqrt{R D_{\text {expected }}}}{O D F}
$$

QI is directly related to detection sensitivity (see Additional file 1 for the exact formula and its derivation), as shown in Figure 5B. According to our power calculations, for the posterior detection threshold value we used in this study $(h=0.65)$, sensitivity is completely diminished for genes with $\mathrm{QI}<5.1$. QI $\geq 7.2$ is required to achieve $50 \%$ sensitivity, and $\mathrm{QI} \geq 9.5$ to achieve $90 \%$ sensitivity. This estimated sensitivity from QI is made only for heterozygous deletions. To achieve the same sensitivity for detecting higher copy number variation $(\mathrm{CN} \geq 3)$, higher $\mathrm{QI}$ value will be required since the difference of prior probability between higher copy and normal copy $(\mathrm{CN}=2)$ is greater than that between heterozygous deletion and normal copy (Table 8).

The distributions of QI values in our three datasets are shown in Figure 5C. Overall, QI was highest in SC: $9.4 \pm 8.8$ (median 6.6); second highest in $\mathrm{BI}: \mathrm{QI}=7.6 \pm$ 5.6 (median 6.2); and lowest in BCM: QI $=5.5 \pm 2.3$ (median 5.0). The corresponding distributions of detection efficiency values are shown in Figure 5A. Because detection efficiency increases abruptly from 0 to almost 1 over a narrow range of QI values (note the mapping between the vertical axes in Figure 5B), the distribution of detection sensitivity (Figure 5A) is strongly bimodal, with the vast majority of GSS having either close to zero or close to $100 \%$ sensitivity. Even in the SC dataset with the highest overall QI values, in less than half of the GSS does the quantity and quality of the data support $>80 \%$ detection efficiency. There was also very substantial variation across samples: only 15 of the 106 SC samples had sufficiently high coverage to support $\geq 90 \%$ overall sensitivity, and in 22 samples overall sensitivity was below $10 \%$.

Given that QI improves only with the square root of RD, over-dispersion can profoundly influence detection performance, as shown in Figure 5B. The ODF values we chose for this figure correspond to the $25^{\text {th }}, 50^{\text {th }}$ and $75^{\text {th }}$ percentile, and the mean values $(\mathrm{ODF}=3,5.5,10$, and 8 , respectively) in the SC dataset. Using the observed distribution of QI in the SC dataset, we predict 46\% sensitivity, in good agreement with our estimate based on simulations.

The QI formulation permits one to estimate CNV (or specifically in our case, heterozygous deletion) detection power in any given exon capture dataset, based on the read mappings. One can also use the formulation to calculate the amount of base coverage required for a given level of desired power, to guide data collection. For example, using the distributions of QI values in the SC dataset, one would need to collect an overall $110 \times$ coverage, assuming 36 bp reads, to achieve $60 \%$ detection power, and $320 \times$ coverage to achieve $80 \%$ detection power. However, if DNA capture methods improved to support a median $\mathrm{ODF}=3$, assuming an accordingly scaled version of the observed distribution of QI in the SC dataset, one would only need to collect $33 \times$ coverage for $60 \%$ power, and $96 \times$ for $80 \%$ power. It is important to also point out that, in the case of whole-exome data, sensitivity would also improve just by virtue of the higher density of targeted genes, if one were to integrate in one's pipeline neighbor-gene based detection.

\section{Methodology comparison with CoNIFER}

Krumm and his colleagues recently published a method, CoNIFER [18], that also used read-depth signal to detect $\mathrm{CNV}$ in the exome capturing sequencing data. Like our method, CoNIFER normalizes the read depth signal in order to discover the CNV. However, it is quite different for these two algorithms in the approach of calling samples copy number variants on the basis that they present aberrant read depth. As we mentioned previously, our method deploys specific models for copy numbers $0,1,2$, and is capable of detecting both rare, intermediate frequency, and common CNV events. On the other hand, CoNIFER deploys singular value decomposition (SVD) to remove noise from the read depth data, and interprets the first " $\mathrm{k}$ " singular values as noise in the data. This approach may identify systematic variance in the data caused by 
Table 5 Gene deletion calls in the BI dataset

\begin{tabular}{|c|c|c|c|c|c|c|c|c|c|}
\hline Population & Sample & Gene name & Gene function & Chr & Start [bp] & End [bp] & $\begin{array}{l}\text { Posterior } \\
\text { probability }\end{array}$ & $R D_{\text {observed }}$ & $R D_{\text {expected }}$ \\
\hline $\mathrm{CHD}$ & NA18695 & TPM3 & tropomyosin 3 & 1 & 152396739 & 152422219 & 1.000 & 166 & 337 \\
\hline JPT & NA19066 & TPM3 & tropomyosin 3 & 1 & 152396739 & 152422219 & 1.000 & 169 & 288 \\
\hline $\mathrm{CHD}$ & NA18687 & RPL27A & ribosomal protein L27a & 11 & 8661325 & 8663929 & 1.000 & 93 & 182 \\
\hline JPT & NA18983 & POU5F1 & POU class 5 homeobox 1 & 6 & 31240357 & 31241803 & 1.000 & 122 & 256 \\
\hline JPT & NA19066 & POU5F1 & POU class 5 homeobox 1 & 6 & 31240357 & 31241803 & 1.000 & 166 & 318 \\
\hline JPT & NA19066 & RPL27A & ribosomal protein $\mathrm{L} 27 \mathrm{a}$ & 11 & 8661325 & 8663929 & 1.000 & 106 & 203 \\
\hline $\mathrm{CHD}$ & NA18687 & TPM3 & tropomyosin 3 & 1 & 152396739 & 152422219 & 1.000 & 155 & 258 \\
\hline $\mathrm{CHD}$ & NA18687 & POU5F1 & POU class 5 homeobox 1 & 6 & 31240357 & 31241803 & 1.000 & 156 & 285 \\
\hline JPT & NA19054 & TPM3 & tropomyosin 3 & 1 & 152396739 & 152422219 & 1.000 & 135 & 230 \\
\hline $\mathrm{CHD}$ & NA18695 & POU5F1 & POU class 5 homeobox 1 & 6 & 31240357 & 31241803 & 1.000 & 194 & 371 \\
\hline JPT & NA18960 & SETD8 & $\begin{array}{l}\text { SET domain containing (lysine } \\
\text { methyltransferase) } 8\end{array}$ & 12 & 122441130 & 122455574 & 1.000 & 221 & 347 \\
\hline $\mathrm{CHD}$ & NA18164 & RPL27A & ribosomal protein $\mathrm{L} 27 \mathrm{a}$ & 11 & 8661325 & 8663929 & 1.000 & 129 & 223 \\
\hline JPT & NA19054 & POU5F1 & POU class 5 homeobox 1 & 6 & 31240357 & 31241803 & 1.000 & 130 & 254 \\
\hline $\mathrm{CHD}$ & NA18695 & SETD8 & $\begin{array}{l}\text { SET domain containing (lysine } \\
\text { methyltransferase) } 8\end{array}$ & 12 & 122441130 & 122455574 & 1.000 & 142 & 309 \\
\hline $\mathrm{CHD}$ & NA18695 & RPL27A & ribosomal protein L27a & 11 & 8661325 & 8663929 & 1.000 & 128 & 238 \\
\hline $\mathrm{CHD}$ & NA18695 & AKR1B1 & $\begin{array}{l}\text { aldo-keto reductase family } 1 \text {, } \\
\text { member B1 (aldose reductase) }\end{array}$ & 7 & 133778020 & 133787045 & 1.000 & 310 & 554 \\
\hline $\mathrm{CHD}$ & NA18164 & $\mathrm{HAX} 1$ & HCLS1 associated protein X-1 & 1 & 152512874 & 152514801 & 1.000 & 214 & 339 \\
\hline $\mathrm{CHD}$ & NA18687 & SETD8 & $\begin{array}{l}\text { SET domain containing (lysine } \\
\text { methyltransferase) } 8\end{array}$ & 12 & 122441130 & 122455574 & 1.000 & 125 & 237 \\
\hline JPT & NA19054 & HFE & hemochromatosis & 6 & 26201326 & 26202433 & 1.000 & 56 & 122 \\
\hline JPT & NA18983 & RPL27A & ribosomal protein L27a & 11 & 8661325 & 8663929 & 0.990 & 95 & 164 \\
\hline JPT & NA18983 & TPM3 & tropomyosin 3 & 1 & 152396739 & 152422219 & 0.990 & 147 & 232 \\
\hline JPT & NA19561 & TRIM55 & tripartite motif-containing 55 & 8 & 67202058 & 67209944 & 0.990 & 119 & 193 \\
\hline $\mathrm{CHD}$ & NA18687 & RBMS1 & $\begin{array}{l}\text { RNA binding motif, single stranded } \\
\text { interacting protein } 1\end{array}$ & 2 & 160840394 & 160932124 & 0.990 & 334 & 575 \\
\hline $\mathrm{CHB}$ & NA18757 & CRIPAK & cysteine-rich PAK1 inhibitor & 4 & 1378300 & 1379640 & 0.990 & 327 & 669 \\
\hline JPT & NA19054 & PSAT1 & phosphoserine aminotransferase 1 & 9 & 80109471 & 80113319 & 0.980 & 140 & 253 \\
\hline JPT & NA19066 & PSAT1 & phosphoserine aminotransferase 1 & 9 & 80109471 & 80113319 & 0.980 & 190 & 317 \\
\hline $\mathrm{CHD}$ & NA18164 & TPM3 & tropomyosin 3 & 1 & 152396739 & 152422219 & 0.980 & 209 & 317 \\
\hline JPT & NA19568 & OR8A1 & $\begin{array}{l}\text { olfactory receptor, family } 8 \text {, } \\
\text { subfamily A, member } 1\end{array}$ & 11 & 123945175 & 123946141 & 0.980 & 471 & 764 \\
\hline JPT & NA19066 & RAN & RAN, member RAS oncogene family & 12 & 129923334 & 129926424 & 0.980 & 229 & 462 \\
\hline $\mathrm{CHD}$ & NA18695 & KLHL12 & kelch-like 12 & 1 & 201128284 & 201160913 & 0.970 & 767 & 1358 \\
\hline JPT & NA19066 & SETD8 & $\begin{array}{l}\text { SET domain containing (lysine } \\
\text { methyltransferase) } 8\end{array}$ & 12 & 122441130 & 122455574 & 0.970 & 154 & 265 \\
\hline JPT & NA19066 & RPS15A & ribosomal protein S15a & 16 & 18706886 & 18707936 & 0.960 & 83 & 161 \\
\hline $\mathrm{CHD}$ & NA18695 & RPS15A & ribosomal protein S15a & 16 & 18706886 & 18707936 & 0.960 & 88 & 188 \\
\hline $\mathrm{CHD}$ & NA18687 & KLHL12 & kelch-like 12 & 1 & 201128284 & 201160913 & 0.960 & 621 & 1041 \\
\hline JPT & NA18983 & SETD8 & $\begin{array}{l}\text { SET domain containing (lysine } \\
\text { methyltransferase) } 8\end{array}$ & 12 & 122441130 & 122455574 & 0.960 & 120 & 213 \\
\hline JPT & NA18983 & DCTN5 & dynactin 5 (p25) & 16 & 23560365 & 23585966 & 0.960 & 177 & 298 \\
\hline JPT & NA18983 & EIF2B5 & $\begin{array}{l}\text { eukaryotic translation initiation factor } \\
2 \mathrm{~B} \text {, subunit } 5 \text { epsilon, } 82 \mathrm{kDa}\end{array}$ & 3 & 185500333 & 185509372 & 0.940 & 856 & 1482 \\
\hline $\mathrm{CHD}$ & NA18687 & ARG2 & arginase, type II & 14 & 67187855 & 67187951 & 0.940 & 28 & 62 \\
\hline
\end{tabular}


Table 5 Gene deletion calls in the BI dataset (Continued)

\begin{tabular}{|c|c|c|c|c|c|c|c|c|c|}
\hline $\mathrm{CHD}$ & NA18695 & PSAT1 & phosphoserine aminotransferase 1 & 9 & 80109471 & 80113319 & 0.930 & 221 & 371 \\
\hline $\mathrm{CHD}$ & NA18695 & RBMS1 & $\begin{array}{l}\text { RNA binding motif, single stranded } \\
\text { interacting protein } 1\end{array}$ & 2 & 160840394 & 160932124 & 0.900 & 442 & 750 \\
\hline JPT & NA19561 & OR8A1 & $\begin{array}{l}\text { olfactory receptor, family } 8 \text {, } \\
\text { subfamily A, member } 1\end{array}$ & 11 & 123945175 & 123946141 & 0.890 & 254 & 466 \\
\hline YRI & NA19247 & TIMM8B & $\begin{array}{l}\text { translocase of inner mitochondrial } \\
\text { membrane } 8 \text { homolog B (yeast) }\end{array}$ & 11 & 111461229 & 111462657 & 0.880 & 40 & 89 \\
\hline $\mathrm{CHD}$ & NA18164 & POU5F1 & POU class 5 homeobox 1 & 6 & 31240357 & 31241803 & 0.850 & 226 & 349 \\
\hline $\mathrm{CHD}$ & NA18164 & KLHL12 & kelch-like 12 (Drosophila) & 1 & 201128284 & 201160913 & 0.800 & 803 & 1276 \\
\hline $\mathrm{CHD}$ & NA18164 & SETD8 & $\begin{array}{l}\text { SET domain containing (lysine } \\
\text { methyltransferase) } 8\end{array}$ & 12 & 122441130 & 122455574 & 0.790 & 181 & 291 \\
\hline $\mathrm{CHD}$ & NA18687 & RPS15A & ribosomal protein S15a & 16 & 18706886 & 18707936 & 0.790 & 81 & 144 \\
\hline JPT & NA19066 & EIF2B5 & $\begin{array}{l}\text { eukaryotic translation initiation } \\
\text { factor } 2 \mathrm{~B} \text {, subunit } 5 \text { epsilon, } 82 \mathrm{kDa}\end{array}$ & 3 & 185500333 & 185509372 & 0.780 & 1137 & 1840 \\
\hline JPT & NA19568 & GABARAPL2 & $\begin{array}{l}\text { GABA }(\mathrm{A}) \text { receptor-associated } \\
\text { protein-like } 2\end{array}$ & 1 & 157676173 & 157676631 & 0.760 & 254 & 476 \\
\hline JPT & NA19560 & OR8A1 & $\begin{array}{l}\text { olfactory receptor, family } 8 \text {, } \\
\text { subfamily A, member } 1\end{array}$ & 11 & 123945175 & 123946141 & 0.750 & 614 & 1119 \\
\hline JPT & NA19058 & RPL27 & ribosomal protein L27 & 17 & 38404294 & 38408463 & 0.730 & 356 & 518 \\
\hline $\mathrm{CHD}$ & NA18699 & SDPR & serum deprivation response & 2 & 192408894 & 192419896 & 0.720 & 524 & 1033 \\
\hline JPT & NA18983 & SPRR2G & small proline-rich protein $2 \mathrm{G}$ & 1 & 151388989 & 151389210 & 0.670 & 81 & 147 \\
\hline JPT & NA19066 & SPRR2G & small proline-rich protein $2 \mathrm{G}$ & 1 & 151388989 & 151389210 & 0.670 & 105 & 182 \\
\hline JPT & NA19066 & RBMS1 & $\begin{array}{l}\text { RNA binding motif, single stranded } \\
\text { interacting protein } 1\end{array}$ & 2 & 160840394 & 160932124 & 0.670 & 404 & 642 \\
\hline JPT & NA19054 & EIF2B5 & $\begin{array}{l}\text { eukaryotic translation initiation } \\
\text { factor } 2 \mathrm{~B} \text {, subunit } 5 \text { epsilon, } 82 \mathrm{kDa}\end{array}$ & 3 & 185500333 & 185509372 & 0.670 & 869 & 1470 \\
\hline $\mathrm{CHD}$ & NA18695 & RAN & RAN, member RAS oncogene family & 12 & 129923334 & 129926424 & 0.660 & 290 & 539 \\
\hline
\end{tabular}

a high-frequency $\mathrm{CNV}$ event as noise and removes it. Therefore CoNIFER has limited power for detecting common $\mathrm{CNV}$ events. On the other hand, our method is capable of detecting CNV events on the entire frequency spectrum, and is therefore more generally applicable.

\section{Conclusions}

We have developed a novel, Bayesian method to identify CNVs in exon-capture data. We applied this method (and a simple extension using neighbor-gene information) to the 1000 Genomes Project Exon
Sequencing Pilot dataset. We were able to achieve reasonable sensitivity and specificity in a dataset that was optimized for SNP discovery and, as discussed above, is far from ideal for CNV detection. The main accomplishment of this work is that we provide a statistically rigorous algorithm for $\mathrm{CNV}$ detection in exon capture data, backed by experimental validations, that can be applied to the thousands of exomes sequenced to date in various medical projects, and to nascent and ongoing projects targeting increasingly higher numbers of samples. Our formulation allows investigators to assess detection power in existing datasets and to take into

Table 6 Gene deletion calls in the BCM dataset

\begin{tabular}{|c|c|c|c|c|c|c|c|c|c|}
\hline Population & Sample & Gene name & Gene function & Chr & Start [bp] & End $[\mathrm{bp}]$ & $\begin{array}{l}\text { Posterior } \\
\text { probability }\end{array}$ & $R D_{\text {observed }}$ & $R D_{\text {expected }}$ \\
\hline LWK & NA19355 & MBD5 & methyl-CpG binding domain protein 5 & 2 & 148932798 & 148986980 & 0.999 & 618 & 973 \\
\hline $\mathrm{CHD}$ & NA17970 & MTERFD2 & MTERF domain containing 2 & 2 & 241684086 & 241687982 & 0.996 & 255 & 393 \\
\hline $\mathrm{CHB}$ & NA18618 & GABARAPL2 & $\begin{array}{l}\mathrm{GABA}(\mathrm{A}) \text { receptor-associated } \\
\text { protein-like } 2\end{array}$ & 16 & 74159436 & 74168768 & 0.800 & 58 & 99 \\
\hline $\mathrm{CHD}$ & NA18135 & PSMB4 & $\begin{array}{l}\text { proteasome (prosome, macropain) } \\
\text { subunit, beta type, } 4\end{array}$ & 1 & 149638688 & 149640929 & 0.729 & 390 & 605 \\
\hline
\end{tabular}




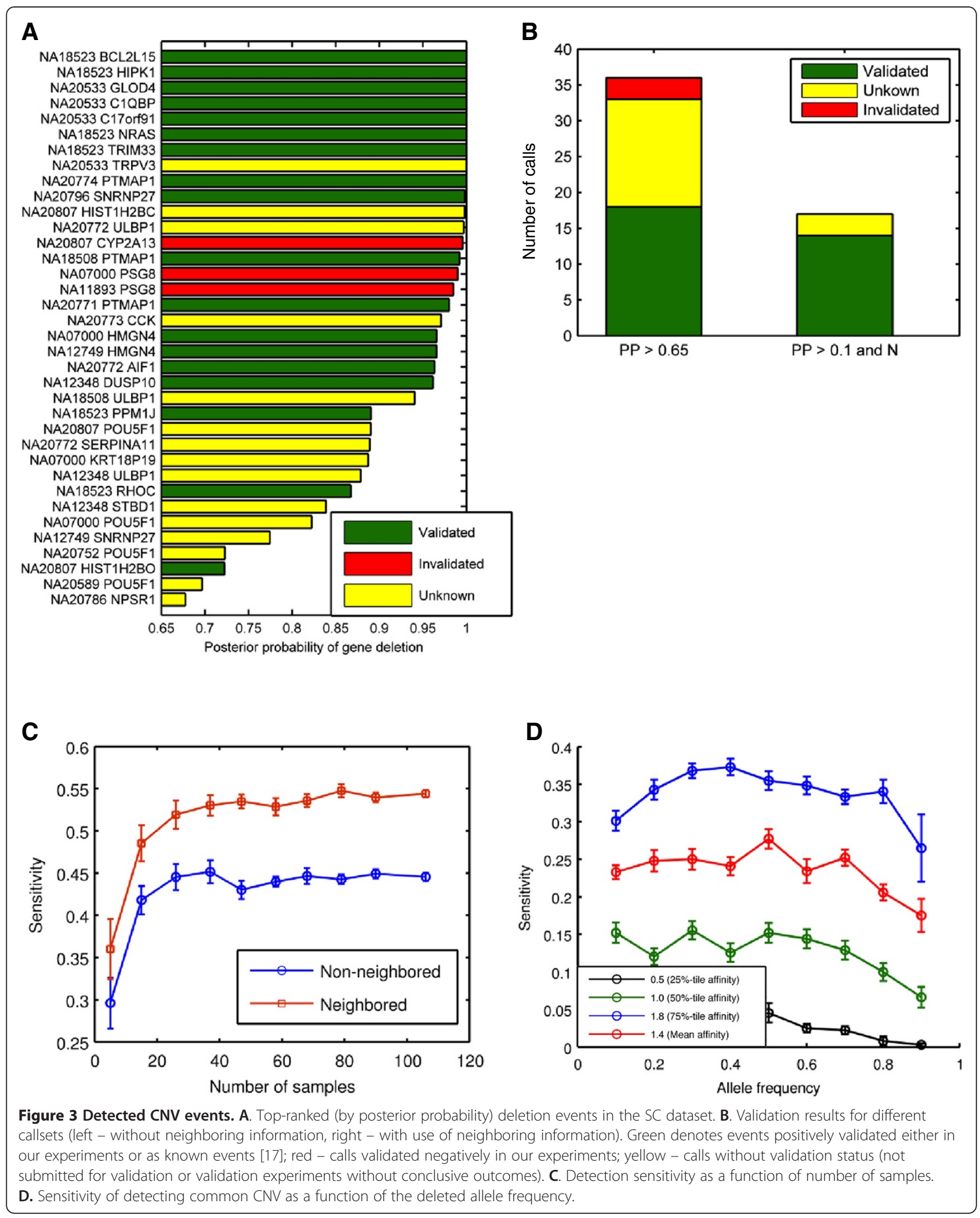


Table 7 Validation results

\begin{tabular}{llll}
\hline & $\begin{array}{l}\text { Posterior } \geq \mathbf{0 . 9 5} \text { without } \\
\text { neighbor information }\end{array}$ & $\begin{array}{l}\mathbf{0 . 6 5} \leq \text { Posterior }<0.95 \text { without } \\
\text { neighbor information }\end{array}$ & $\begin{array}{l}\text { Posterior } \geq \mathbf{0 . 1} \text { with } \\
\text { neighbor information }\end{array}$ \\
\hline Validated per previous publication & 4 & 2 & 7 \\
Validated positively de novo & 11 & 1 & 7 \\
Validated inconclusively de novo (intermediate fold change) & 4 & 1 & 0 \\
Validated negatively de novo & 3 & 0 & 0 \\
$\begin{array}{l}\text { Submitted for validation but without result or no validation } \\
\text { attempt }\end{array}$ & 0 & 10 & 3 \\
Total calls & 22 & 14 & 17 \\
\hline
\end{tabular}

account $\mathrm{CNV}$ detection power during experimental design for future datasets. We also uncovered $>100$ heterozygous deletion events in the 1000 Genomes samples we examined, allowing us to estimate the average number of heterozygous deletions per exome (as $\sim 16$ events per exome). Because we focused on algorithm development functional assessment of these sites is beyond the scope of this study. Nevertheless, these and other gene deletions that will be found using our methods are very likely to uncover events with strong functional significance.

\section{Methods}

The overall detection workflow (shown in Figure 1) consists of three main steps. (1) We tabulate the observed read depth for every GSS. (2) We determine whether the distribution of read depth for a specific gene distribute across samples should be modeled using simple unilinear fit or using a more sophisticated tri-linear fit. (3) If the simple uni-linear fit is found suitable, we determine an expected read depth for every GSS under a null hypothesis of a normal copy number, using a simple linear fit model. (4) Subsequently, we compare the observed read depth for a GSS to the corresponding expectation and calculate a Bayesian posterior probability for each copy number considered $(\mathrm{CN}=0-9)$, threshold these, and report events with a non-normal CN. (5) If data do not allow for modeling using a simple uni-linear fit model, we perform a more sophisticated tri-linear fit. The trilinear fit directly assigns copy number to every sample.

\section{Observed read depth}

Capture sequencing reads from the 1000 Genomes Project Exon Sequencing Pilot Project were downloaded, in FASTQ format, from the 1000 Genomes Project DCC site: http://1000genomes.org. The reads were mapped using the MOSAIK read mapping program, to the NCBI build 36.3 human reference genome. The resulting read alignments (in BAM format) were further processed to remove duplicate reads, and reads with low mapping quality $(<20)$.

Gene target regions were also downloaded from the 1000 Genomes Project site. For each GSS, we determined RD as the number of distinct reads that had their first (5') base uniquely mapped within an exon of that gene. This resulted in a matrix of RD observations (illustrated in Figure 1C left).
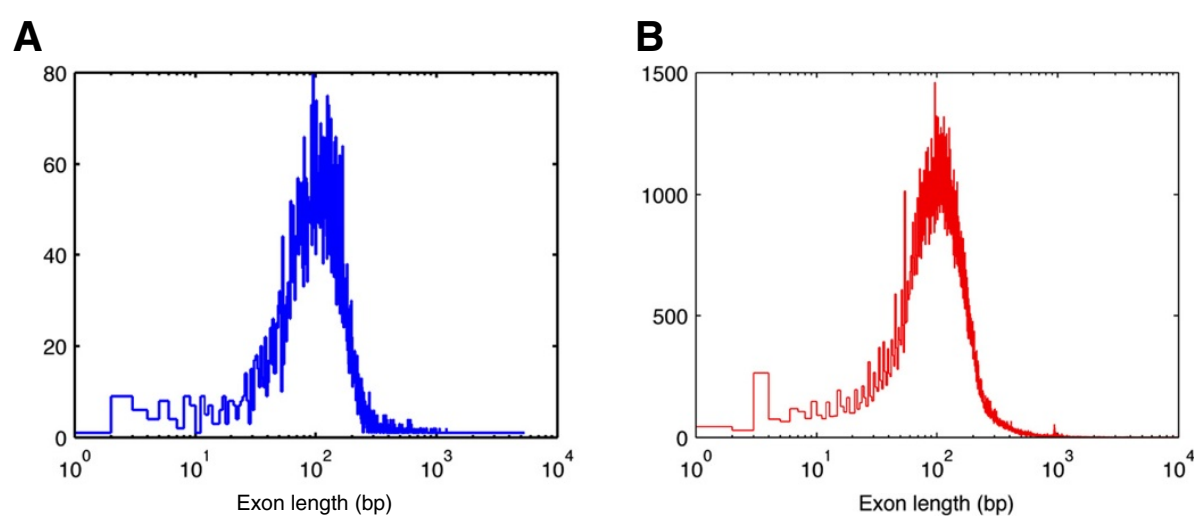

Figure 4 Exon length distribution. A. Exon length distribution in the gene list used for our analysis. (median: 125 bp, standard deviation: 236 bp) B. Exon length distribution of the whole exome. (median: 127 bp, standard deviation: 264 bp) These two distributions are very similar to each other, suggesting our estimation of the number of events per sample is unbiased and is representative for a whole-exome study. 


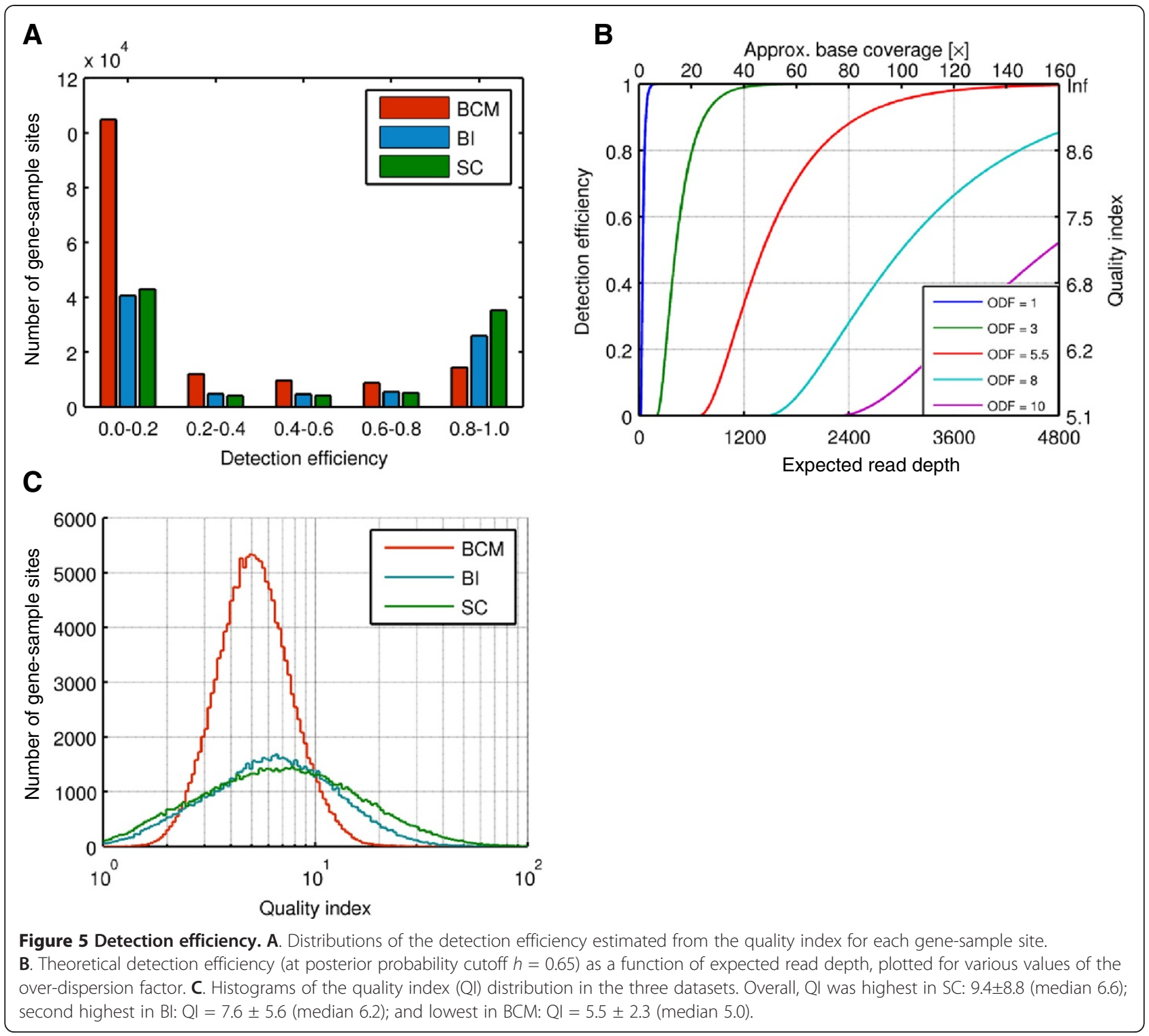

Table 8 Nominal prior probabilities corresponding to the range of gene region copy numbers derived from Conrad et al. [17]

\begin{tabular}{ll}
\hline Copy number & Prior probability per gene \\
\hline 0 & $6.34 \cdot 10^{-4}$ \\
1 & $2.11 \cdot 10^{-3}$ \\
2 & $9.96 \cdot 10^{-1}$ \\
3 & $5.38 \cdot 10^{-4}$ \\
4 & $6.68 \cdot 10^{-4}$ \\
5 & $3.57 \cdot 10^{-5}$ \\
6 & $7.52 \cdot 10^{-6}$ \\
7 & $1.39 \cdot 10^{-6}$ \\
8 & $3.61 \cdot 10^{-7}$ \\
9 & $4.37 \cdot 10^{-8}$ \\
\hline
\end{tabular}

\section{Data filtering}

We discarded all duplicate reads and all reads with mapping quality less than 20 . We also discarded all the targets with median RD less than 30. Similarly, we discarded all the samples with median RD less than 30. In 454-sequenced data, this led to discarding almost all targets and samples; therefore we relaxed those criteria to 5 and 1, respectively. Additionally, we discarded all the genes that failed to exhibit correlation between observed RD and MRD at $r^{2} \geq 0.7$.

\section{Expected read depth based on uni-linear fit and tri-linear fit}

In the first attempt, we use the simple uni-linear fit; we calculate the expected read depth for normal copy number $(\mathrm{CN}=2)$ as the product of a gene-specific capture 
affinity value, $\alpha_{\mathrm{g}}$, and a sample-specific measure of read coverage, the median of read depths, $M R D_{\mathrm{s}}$, across all genes for that sample:

$$
R D_{g s}=\alpha_{g} \cdot M R D_{s}
$$

The gene-specific capture affinity $\left(\alpha_{\mathrm{g}}\right)$ is determined as the slope of a least-squares zero-intercept linear fit between the gene-specific read depth $\left(R D_{\mathrm{gs}}\right)$ and the median read depth $\left(M R D_{\mathrm{s}}\right)$ for all samples (illustrated in Figure 1B). This procedure resulted in a matrix of RD expectations (Figure $1 \mathrm{C}$ right).

The afore-mentioned procedure requires a single-line linear fit between $R D_{\mathrm{gs}}$ and $M R D_{\mathrm{s}}$. The quality of such a fit is evaluated by comparing $r^{2}$ against a predetermined threshold ( $\geq 0.7$ as described before). When this indicates poor quality of the single-line linear fit, we attempt to perform a tri-linear fit.

Briefly, we attempted to minimize error function

$$
\begin{aligned}
\text { error }_{g}= & \sum_{s} \min \left\{\left(R D_{g, s}-\alpha_{g} M R D_{s}\right)^{2},\right. \\
& \left.\left(R D_{g, s}-\frac{\alpha_{g}}{2} M R D_{s}\right)^{2},\left(R D_{g, s}-0 . M R D_{s}\right)^{2}\right\},
\end{aligned}
$$

where $s$ iterates over samples and g indicates the gene in question. Note that the tri-linear fit directly assigns copy number to each GSS. Please see Common CNVs for more detail.

\section{Copy number probabilities}

We used a Bayesian scheme to calculate the probability $\mathrm{P}\left(C N_{g s} \mid R D_{g s}\right.$ of a given copy number at a given GSS, based on the observed read depth. We only considered $\mathrm{CN}=0-9$ i.e. homozygous deletion $(\mathrm{CN}=0)$, heterozygous deletion $(\mathrm{CN}=1)$, normal copy number $(\mathrm{CN}=2)$, and amplifications of various magnitudes $(\mathrm{CN}>2)$. We assigned prior probabilities $\mathrm{P}\left(\mathrm{CN}_{\mathrm{gs}}\right)$ to each copy number based on $\mathrm{CNV}$ events reported in an earlier study [17] (Table 8). We assumed that, for each distinct CN, the observed RD obeys an over-dispersed Poisson distribution. Its mean value for normal copy number $(\mathrm{CN}=2)$ is calculated according to (Eq. 2) and for other copy numbers it is proportionally scaled. The standard deviation of the distribution includes an over-dispersion factor (ODF) in the range of 1 to 20 to account for overdispersion (variance beyond the level of Poisson fluctuations, see Additional file 1).

Briefly, to account for over-Poisson dispersion, we used observed $\mathrm{RD}_{\mathrm{gs}}$ and calculated corresponding $z$-score under an assumption of an ideal Poisson distribution at every GSS. Subsequently, we calculated a sample-specific standard deviation of that $z$-score for every sample and annotated it as sample over-dispersion factor. Similarly, we calculated a gene-specific standard deviation of $z$-score for every gene and annotated it as the gene-specific over-dispersion factor. If the assumption of an ideal Poisson distribution were true, those sample- and gene-specific standard deviations should equal 1 . Subsequently, we calculated the over-dispersion factor for every GSS as a product of respective sample- and gene-specific ODFs. The ODF was then normalized and assigned to 1 if less than 1.

We used the over-dispersed Poisson distributions to calculate the data likelihoods $\mathrm{P}\left(R D_{\mathrm{gs}} \mid C N\right)$ for all considered $\mathrm{CN}$ values. Finally, we used Bayes' method to estimate the posteriors for each considered $\mathrm{CN}$. A CNV event is reported the posterior probability of a non-normal copy number is above a pre-defined threshold value, $h$.

\section{Neighboring gene deletions}

A simple extension of the algorithm used neighboring gene deletion events as part of the detection method. For the purpose of our algorithm, the genes were deemed "neighboring" if they were located on the same chromosome, the segment between those genes was no longer than $3 \mathrm{Mbp}$ and no gene was sequenced in between. In principle, when a gene has a deleted neighbor, we should assume a higher prior probability of a deletion in the gene in question. Since the posterior probability usually scales monotonically with the prior, for practical reasons we assumed a lower Bayesian posterior probability threshold $(h=0.1)$ to produce a preliminary list of candidate events. Events on this list for which at least one of the two immediate neighbor genes was also on the list were retained.

\section{Sensitivity estimation}

We carried out sensitivity estimation in the SC dataset, using simple simulations. In each simulation cycle, we drew 5 genes randomly from every sample, and downscaled the observed RD for those genes by a factor of 2 , to emulate heterozygous deletions. We then applied our standard detection procedure to this "spiked" dataset, and tabulated the fraction of simulated events that were detected by the algorithm.

\section{Common CNVs}

We evaluated all genes that failed to achieve $r^{2} \geq 0.7$ using the linear fit model from Figure 1B. The results of that evaluation are shown in Figure 6. The last row describes result for gene RNF150 that achieved the worst $r^{2}$ of 0.48 . The histogram shown in the left columns demonstrates distribution of observed RD to MRD (taken as from Figure 1B), In case of a rare CNV (or lack of CNVs at all), one would expect a unimodal distribution centered around that gene affinity. For a common $\mathrm{CNV}$, one additional peak corresponding to $\mathrm{CN}=1$ centered around half of that gene affinity, and another peak corresponding to homozygous deletion $(\mathrm{CN}=0)$ around 0 , should be visible. However, the 

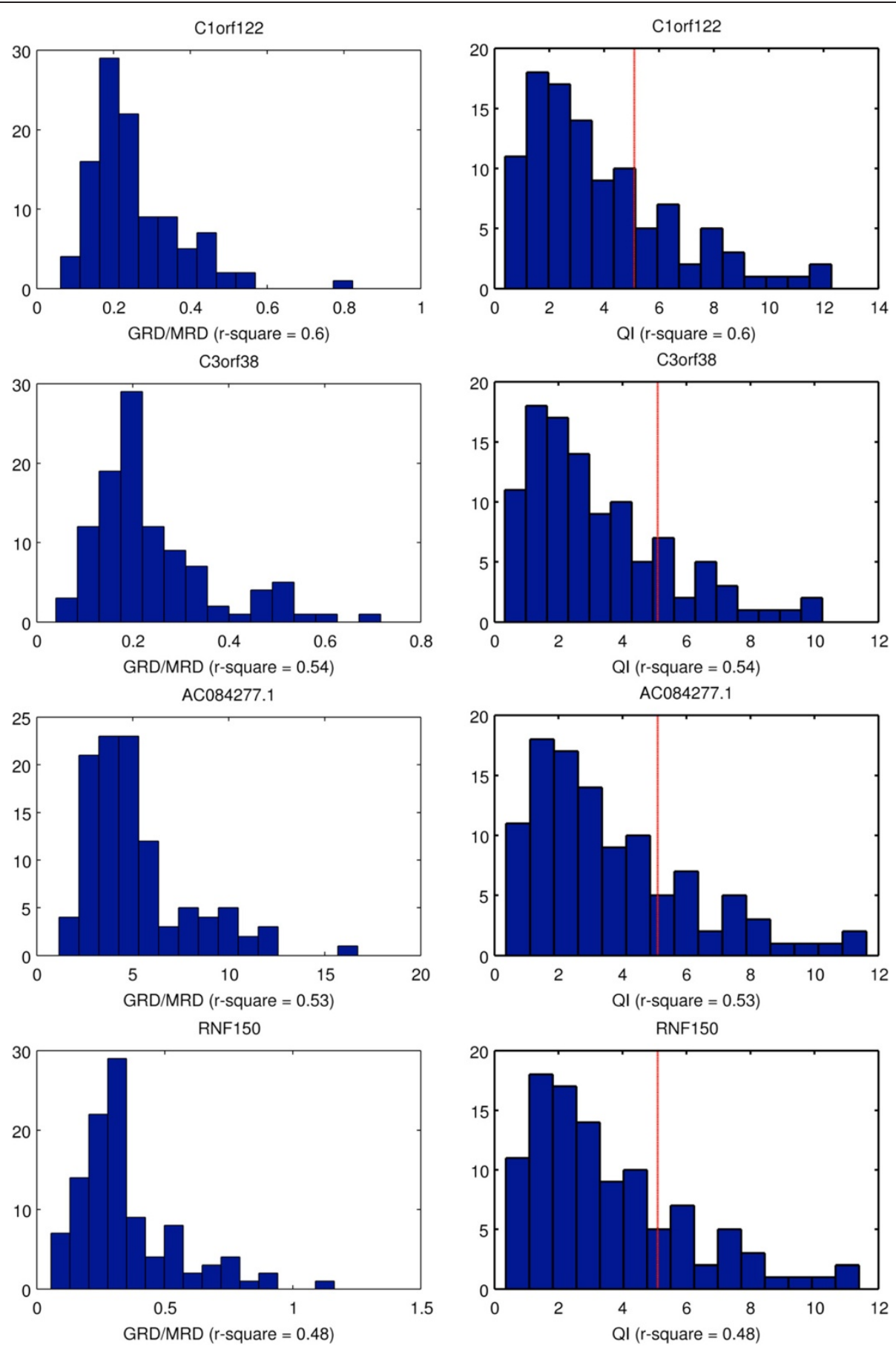

Figure 6 Analysis of genes that failed simple linear fit. Each row describes a different gene. Left panels - distribution of the ratio of RD at the GSS sites to the sample MRD. Right panels - distribution of the quality index for that gene. The non-multimodal distributions and the low qualityindex values of these genes suggest that there are no common CNV events on these loci.

data shown do not allow identifying such a pattern of either bi- or tri-modal distribution.

Additionally, the histogram of quality index calculated for that gene is presented in the right column. The low values of quality index further corroborate the conclusion that the absence of a call in that locus is due to lack of high quality data rather than due to a hypothetical common $\mathrm{CNV}$ event. Careful inspection of the graphs calculated for all 69 genes the failed simple linear fit reveals lack of evidence for a common CNV in any of them. Notably, in the SC dataset only $28 \%$ of GSS in genes with $r^{2}<0.7$ were potentially detectable vs. $62 \%$ in genes with $r^{2} \geq 0.7$. 
With no common CNV present in the experimental data, we tested the sensitivity of our algorithm using simulated deletions. We used realistic gene affinities (mean and three quartiles from Figure 2B) and the empirical MRDs for 106 samples. We assumed frequency of the deleted allele among 106 samples varying from 0 to $100 \%$ in $10 \%$ increments; we allowed for random segregation, so that both homo- and heterozygous deletions were introduced. Then for each sample we calculated the expected read depth as a product of MRD and affinity; however in the samples drawn for a heterozygous deletion we used halves of the nominal affinities and in the samples drawn for a homozygous deletion, we multiplied the MRD by 0.01 to account for reads erroneously mapped into that region. Having an expected read depth $m$ for each sample, we drew a random read depth using a normal distribution $N(m, O D F \sqrt{m}) \sqrt{2}$, where ODF was assumed 8 .

In Figure $7 \mathrm{~B}$ and $\mathrm{C}$ we show the results of analysis performed on simulated common CNV events. Panel B shows $r^{2}$ values obtained from the simple linear fit (as in Figure 1B) and panel $\mathrm{C}$ shows the $r^{2}$ values obtained from the tri-linear fit (as in Figure 7A). The uni-linear $r^{2}$ values deteriorate with the increase of the deleted allele frequency. To the contrary, the tri-linear $r^{2}$ values stay relatively high over wide range of the allele frequency.

Finally, Figure 3D demonstrates that the sensitivity of the algorithm to the common CNVs remains relatively stable over wide range of the deleted allele frequency (up to $90 \%$ ).

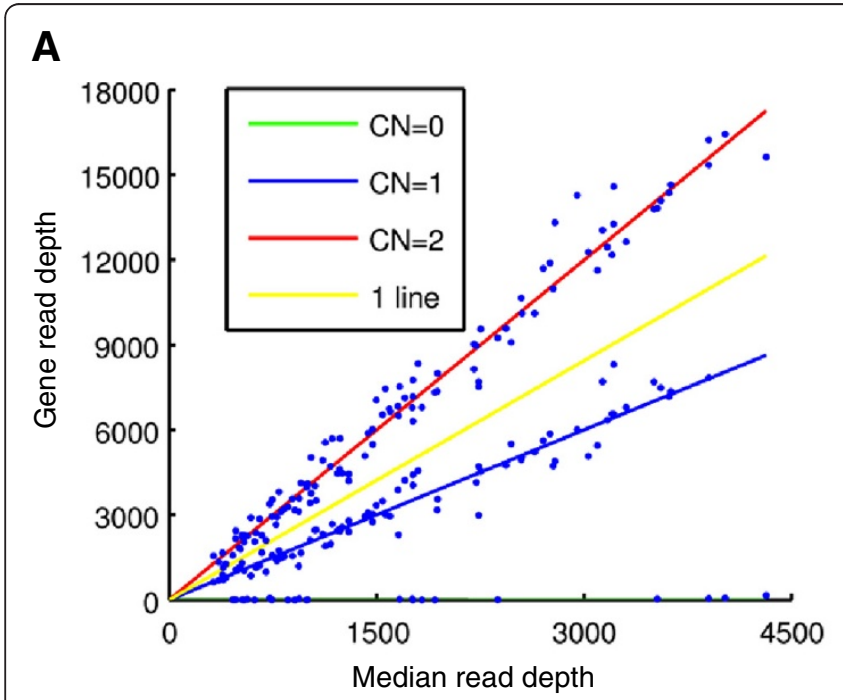

B

C
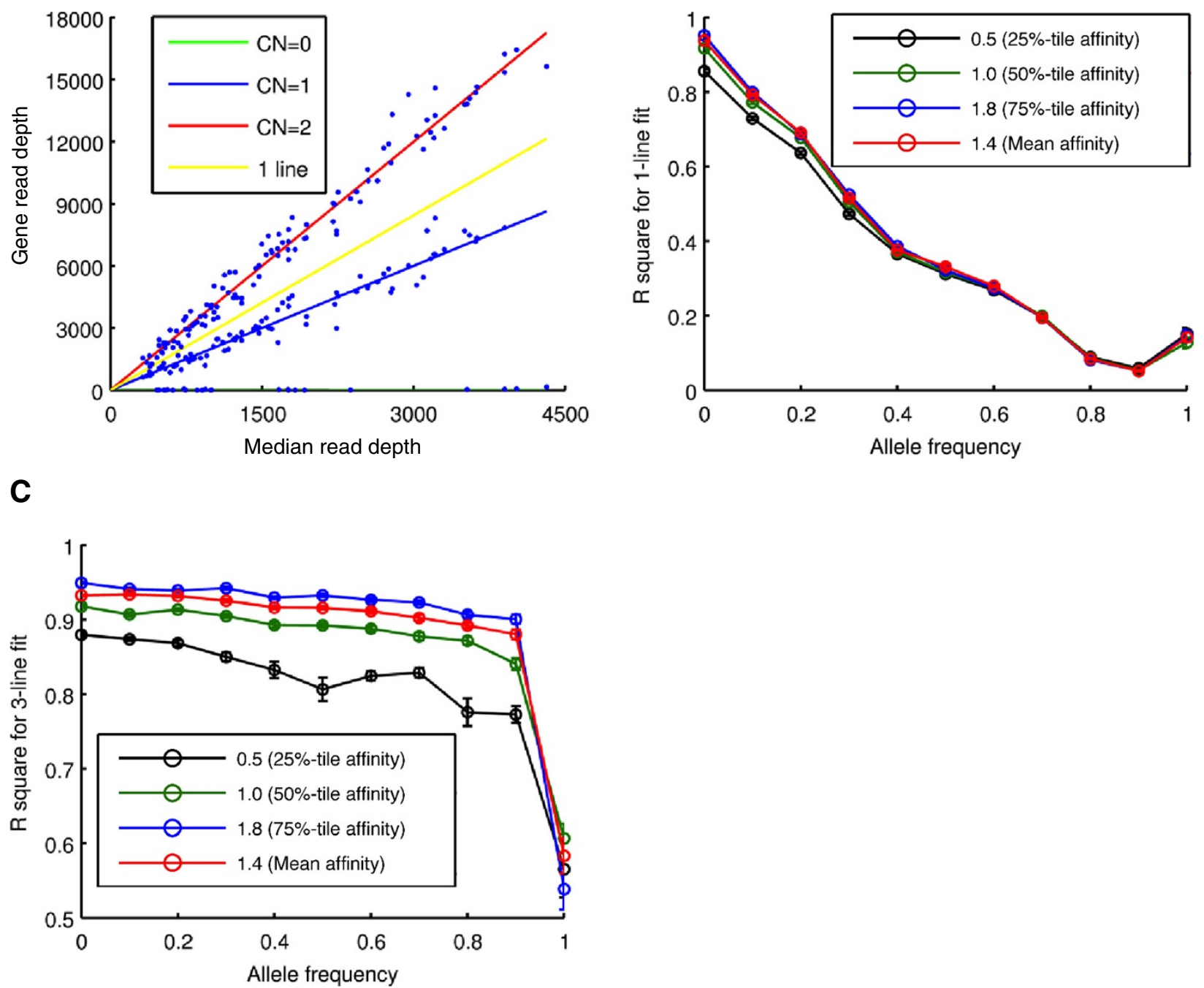

Figure 7 Simulated Common CNVs. A. If a simple linear fit fails, the gene affinity is estimated for each gene as the slope of the least-squareerror tri-linear fit between MRD and RD for that gene. $\mathbf{B}$ and $\mathbf{C} r^{2}$ values of a simple linear fit (B) and a tri-linear fit (C) as a function of the deleted allele frequency. 


\section{Validation experiments}

All primers were designed using primer3 (http://fokker. wi.mit.edu/primer3/) with default settings to obtain a desired PCR amplicon size between $200 \mathrm{bp}$ and $250 \mathrm{bp}$. All primers were checked with BLAT (http://genome. ucsc.edu/) to avoid known SNPs that could influence primer hybridization. PCR products were run on an agarose gel to make sure they gave no additional bands besides the expected amplicon.

Primer efficiencies were determined by calculating the standard curve of a serial dilution (4 times, 10-fold) of pooled genomic DNA (Promega, Madison, WI). All experiments were performed in triplicates on the Roche LightCycler 480 platform with LightCycler 480 SYBR Green I Master (cat\# 04707516001). The volume of each reaction was $20 \mu \mathrm{l}$ with final primer concentrations of $400 \mathrm{nM}$. The PCR was performed according to the following protocol: $5 \mathrm{~min}$ at $95^{\circ} \mathrm{C}, 2.45$ cycles of $5 \mathrm{~s}$ at $95^{\circ} \mathrm{C}, 10 \mathrm{~s}$ at $60^{\circ} \mathrm{C}, 30 \mathrm{~s}$ at $72^{\circ} \mathrm{C}$. To determine the copy number state of an event locus, we used the Delta-Delta-Ct-Method (2- $\Delta \Delta \mathrm{Ct}$ ) for each event locus compared to a reference locus in the sample and a control pool of seven individuals (Promega, Madison, WI), respectively. This reference locus was not previously known to show any copy number variation.

Among the calls made without neighboring information, we exhaustively validated all the calls with posterior probability of 0.95 or more $(4$ coincided with known events [17]; we experimentally validated the remaining 18 events). Additionally, we performed qPCR validations for 4 events randomly selected from those with posterior probability between 0.65 and 0.95 ( 2 coincided with known events [17]; we experimentally validated the remaining 2 events).

Of the calls made with the neighboring information, we deemed 7 calls coincided with known events [17]; 7 out of 10 remaining calls were submitted for qPCR validation. For the purpose of validation, the fold change for a given gene $<0.7$ was classified as a positive validation, $>0.8$ as a negative validation and in the intermediate range as inconclusive.

\section{Additional file}

Additional file 1: Detail formula of over-dispersion factor (ODF) and quality index (QI), give the exact formula and derivation of the over-dispersion factor and quality index.

\section{Abbreviations}

CNV: Copy Number Variation; FDR: False Discovery Rate; RP: Read Pair; SR: Split Read; RD: Read Depth; AS: Assembly; GSS: Gene-Sample Site; WU: Washington University; SC: Wellcome Trust Sanger Institute; Bl: Broad Institute; BCM: Baylor College of Medicine; MRD: Median Read Depth; CN: Copy Number; ODF: Over-Dispersion Factor; QI: Quality Index.

\section{Competing interests}

The authors declare that they have no competing interests.

\section{Authors' contributions}

JW designed algorithms, performed analysis and wrote the paper. KRG designed algorithms, performed analysis, wrote the paper. CS designed algorithms and experiments. FG, AEU and MPS designed and performed the experiments. GTM designed the algorithms, wrote the paper and supervised the project. All authors read and approved the final manuscript.

\section{Acknowledgements}

This work was supported by National Human Genome Research Institute grants R01-HG004719 and RC2-HG005552.

\section{Author details}

${ }^{1}$ Boston College, Boston, Chestnut Hill, MA, USA. ${ }^{2}$ Stanford University School of Medicine, Stanford, CA, USA.

Received: 14 June 2012 Accepted: 7 November 2012

Published: 17 November 2012

\section{References}

1. Sudmant PH, Kitzman JO, Antonacci F, Alkan C, Malig M, Tsalenko A, Sampas N, Bruhn L, Shendure J: 1000 Genomes Project, Eichler EE: Diversity of human copy number variation and multicopy genes. Science 2010, 330(6004):641-646.

2. Fanciulli M, Petretto E, Aitman TJ: Gene copy number variation and common human disease. Clin Genet 2010, 77(3):201-213.

3. Teh MT, Gemenetzidis E, Chaplin T, Young BD, Philpott MP: Upregulation of FOXM1 induces genomic instability in human epidermal keratinocytes. Mol Cancer 2010, 9:45.

4. Frank B, Bermejo JL, Hemminki K, Sutter C, Wappenschmidt B, Meindl A Kiechle-Bahat M, Bugert P, Schmutzler RK, Bartram CR, Burwinkel B: Copy number variant in the candidate tumor suppressor gene MTUS1 and familial breast cancer risk. Carcinogenesis 2007, 28(7):1442-1445.

5. Sebat J, Lakshmi B, Malhotra D, Troge J, Lese-Martin C, Walsh T, Yamrom B, Yoon S, Krasnitz A, Kendall J, Leotta A, Pai D, Zhang R, Lee YH, Hicks J, Spence SJ, Lee AT, Puura K, Lehtimaki T, Ledbetter D, Gregersen PK, Bregman J, Sutcliffe JS, Jobanputra V, Chung W, Warburton D, King MC, Skuse D, Geschwind DH, Gilliam TC, et al: Strong association of de novo copy number mutations with autism. Science 2007, 316(5823):445-449.

6. Kusenda M, Sebat J: The role of rare structural variants in the genetics of autism spectrum disorders. Cytogenet Genome Res 2008, 123(1-4):36-43.

7. Mulle JG, Dodd AF, McGrath JA, Wolyniec PS, Mitchell AA, Shetty AC, Sobreira NL, Valle D, Rudd MK, Satten G, Cutler DJ, Pulver AE, Warren ST: Microdeletions of 3q29 confer high risk for schizophrenia. Am J Hum Genet 2010, 87(2):229-236.

8. lafrate AJ, Feuk L, Rivera MN, Listewnik ML, Donahoe PK, Qi Y, Scherer SW, Lee C: Detection of large-scale variation in the human genome. Nat Genet 2004, 36(9):949-951.

9. Baross A, Delaney AD, Li HI, Nayar T, Flibotte S, Qian H, Chan SY, Asano J, Ally A, Cao M, Birch P, Brown-John M, Fernandes N, Go A, Kennedy G, Langlois S, Eydoux P, Friedman JM, Marra MA: Assessment of algorithms for high throughput detection of genomic copy number variation in oligonucleotide microarray data. BMC Bioinformatics 2007, 8:368.

10. Sebat J, Lakshmi B, Troge J, Alexander J, Young J, Lundin P, Maner S, Massa H, Walker M, Chi M, Navin N, Lucito R, Healy J, Hicks J, Ye K, Reiner A, Gilliam TC, Trask B, Patterson N, Zetterberg A, Wigler M: Large-scale copy number polymorphism in the human genome. Science 2004, 305(5683):525-528

11. Redon R, Ishikawa S, Fitch KR, Feuk L, Perry GH, Andrews TD, Fiegler $H$, Shapero MH, Carson AR, Chen W, Cho EK, Dallaire S, Freeman JL, Gonzalez JR, Gratacos M, Huang J, Kalaitzopoulos D, Komura D, MacDonald JR, Marshall CR, Mei R, Montgomery L, Nishimura K, Okamura K, Shen F, Somerville MJ, Tchinda J, Valsesia A, Woodwark C, Yang F, et al: Global variation in copy number in the human genome. Nature 2006, 444(7118):444-454.

12. Cooper GM, Nickerson DA, Eichler EE: Mutational and selective effects on copy-number variants in the human genome. Nat Genet 2007, 39(7 Suppl):S22-9. 
13. Yoon S, Xuan Z, Makarov V, Ye K, Sebat J: Sensitive and accurate detection of copy number variants using read depth of coverage. Genome Res 2009, 19(9):1586-1592.

14. Mills RE, Walter K, Stewart C, Handsaker RE, Chen K, Alkan C, Abyzov A, Yoon SC, Ye K, Cheetham RK, Chinwalla A, Conrad DF, Fu Y, Grubert F, Hajirasouliha I, Hormozdiari F, lakoucheva LM, labal Z, Kang S, Kidd JM, Konkel MK, Korn J, Khurana E, Kural D, Lam HY, Leng J, Li R, Li Y, Lin CY, Luo $R$, et al: 1000 Genomes Project: Mapping copy number variation by population-scale genome sequencing. Nature 2011, 470(7332):59-65.

15. Sathirapongsasuti JF, Lee H, Horst BA, Brunner G, Cochran AJ, Binder S, Quackenbush J, Nelson SF: Exome sequencing-based copy-number variation and loss of heterozygosity detection: ExomeCNV. Bioinformatics 2011, 27(19):2648-2654.

16. 1000 Genomes Project Consortium: A map of human genome variation from population-scale sequencing. Nature 2010, 467(7319):1061-1073.

17. Conrad DF, Pinto D, Redon R, Feuk L, Gokcumen O, Zhang Y, Aerts J, Andrews TD, Barnes C, Campbell P, Fitzgerald T, Hu M, Ihm CH, Kristiansson K, Macarthur DG, Macdonald JR, Onyiah I, Pang AW, Robson S, Stirrups K, Valsesia A, Walter K, Wei J, Wellcome Trust Case Control C, Tyler-Smith C, Carter NP, Lee C, Scherer SW, Hurles ME: Origins and functional impact of copy number variation in the human genome. Nature 2010 464:704-712. doi:7289.

18. Krumm N, Sudmant PH, Ko A, O'Roak BJ, Malig M, Coe BP: NHLBI Exome Sequencing Project, Quinlan AR, Nickerson DA, Eichler EE: Copy number variation detection and genotyping from exome sequence data. Genome Res 2012, 22(8):1525-1532.

doi:10.1186/1471-2105-13-305

Cite this article as: Wu et al:: Copy Number Variation detection from 1000 Genomes project exon capture sequencing data. BMC

Bioinformatics 2012 13:305.

\section{Submit your next manuscript to BioMed Central and take full advantage of:}

- Convenient online submission

- Thorough peer review

- No space constraints or color figure charges

- Immediate publication on acceptance

- Inclusion in PubMed, CAS, Scopus and Google Scholar

- Research which is freely available for redistribution 